University of Nebraska - Lincoln

DigitalCommons@University of Nebraska - Lincoln

2013

\title{
Ballistic helmets - Their design, materials, and performance against traumatic brain injury
}

\author{
S.G. Kulkarni \\ Texas A\&M University, kulkarni.sameerkulkarni@gmail.com \\ X.-L. Gao \\ University of Texas at Dallas, Xin-Lin.Gao@utdallas.edu \\ S.E. Horner \\ U.S. Army, Fort Belvoir \\ J.Q. Zheng \\ U.S. Army, Fort Belvoir
}

N.V. David

Universiti Teknologi MARA

Follow this and additional works at: https://digitalcommons.unl.edu/usarmyresearch

Kulkarni, S.G.; Gao, X.-L.; Horner, S.E.; Zheng, J.Q.; and David, N.V., "Ballistic helmets - Their design, materials, and performance against traumatic brain injury" (2013). US Army Research. 201.

https://digitalcommons.unl.edu/usarmyresearch/201

This Article is brought to you for free and open access by the U.S. Department of Defense at DigitalCommons@University of Nebraska - Lincoln. It has been accepted for inclusion in US Army Research by an authorized administrator of DigitalCommons@University of Nebraska - Lincoln. 
Review

\title{
Ballistic helmets - Their design, materials, and performance against traumatic brain injury
}

\author{
S.G. Kulkarni ${ }^{\text {a }}$, X.-L. Gao ${ }^{\text {b,* }}$, S.E. Horner ${ }^{\text {c }}$, J.Q. Zheng ${ }^{\text {c }}$, N.V. David ${ }^{\mathrm{d}}$ \\ a Department of Mechanical Engineering, Texas A\&'M University, College Station, TX 77843, United States \\ ${ }^{\mathrm{b}}$ Department of Mechanical Engineering, University of Texas at Dallas, 800 West Campbell Road, Richardson, TX 75080-3021, United States \\ ${ }^{\mathrm{c}}$ Program Executive Office - SOLDIER, U.S. Army, Fort Belvoir, VA 20169, United States \\ ${ }^{\mathrm{d}}$ Faculty of Mechanical Engineering, Universiti Teknologi MARA, 40450 Shah Alam, Selangor, Malaysia
}

\section{A R T I C L E I N F O}

\section{Article history:}

Received 5 October 2012

Received in revised form 4 February 2013

Available online 27 February 2013

\section{Keywords:}

Helmet

Ballistic

Traumatic brain injury

Blast

Impact

Armor

\begin{abstract}
A B S T R A C T
Protecting a soldier's head from injury is critical to function and survivability. Traditionally, combat helmets have been utilized to provide protection against shrapnel and ballistic threats, which have reduced head injuries and fatalities. However, home-made bombs or improvised explosive devices (IEDs) have been increasingly used in theatre of operations since the Iraq and Afghanistan conflicts. Traumatic brain injury (TBI), particularly blast-induced TBI, which is typically not accompanied by external body injuries, is becoming prevalent among injured soldiers. The responses of personal protective equipment, especially combat helmets, to blast events are relatively unknown. There is an urgent need to develop head protection systems with blast protection/mitigation capabilities in addition to ballistic protection. Modern military operations, ammunitions, and technology driven war tactics require a lightweight headgear that integrates protection mechanisms (against ballistics, blasts, heat, and noise), sensors, night vision devices, and laser range finders into a single system. The current article provides a comparative study on the design, materials, and ballistic and blast performance of the combat helmets used by the US Army based on a comprehensive and critical review of existing studies. Mechanisms of ballistic energy absorption, effects of helmet curvatures on ballistic performance, and performance measures of helmets are discussed. Properties of current helmet materials (including Kevlar ${ }^{\circledR} \mathrm{K} 29, \mathrm{~K} 129$ fibers and thermoset resins) and future candidate materials for helmets (such as nano-composites and thermoplastic polymers) are elaborated. Also, available experimental and computational studies on blast-induced TBI are examined, and constitutive models developed for brain tissues are reviewed. Finally, the effectiveness of current combat helmets against TBI is analyzed along with possible avenues for future research.
\end{abstract}

(c) 2013 Elsevier Ltd. All rights reserved.

\section{Contents}

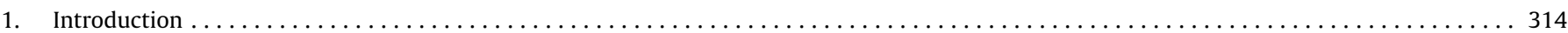

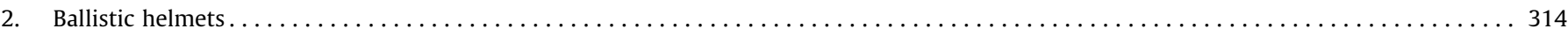

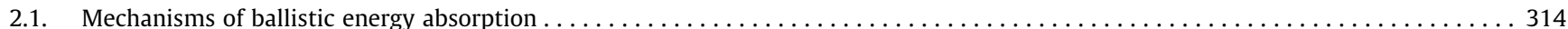

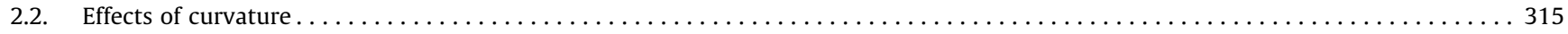

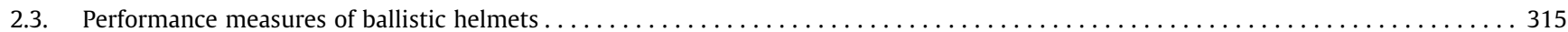

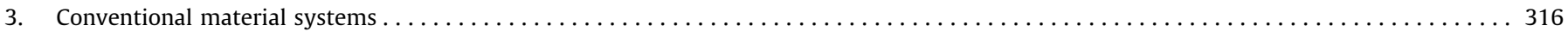

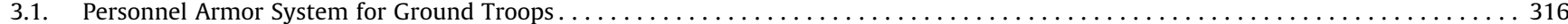

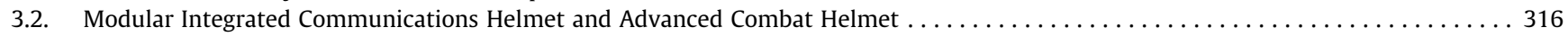

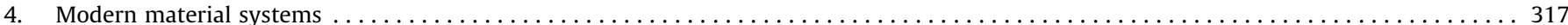

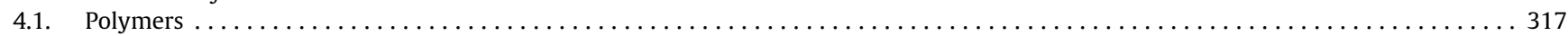

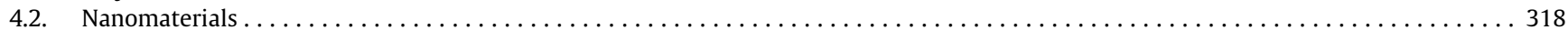

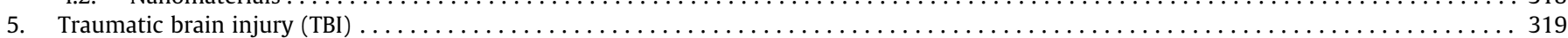

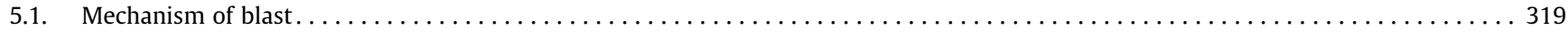

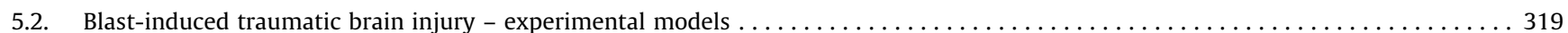

\footnotetext{
* Corresponding author. Tel.: +1 9728834550.

E-mail address: Xin-Lin.Gao@utdallas.edu (X.-L. Gao).
} 


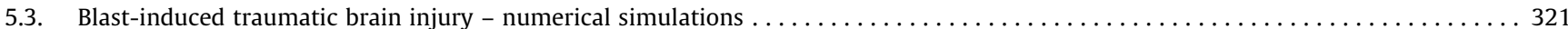

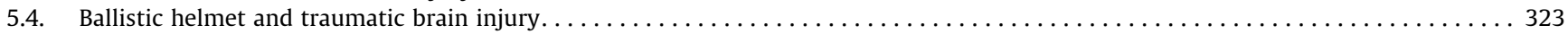

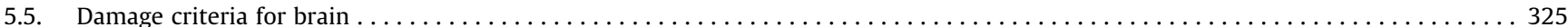

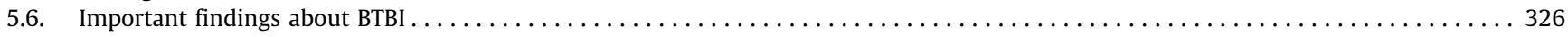

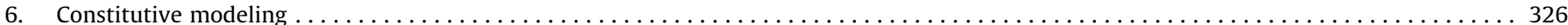

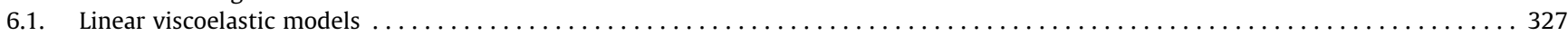

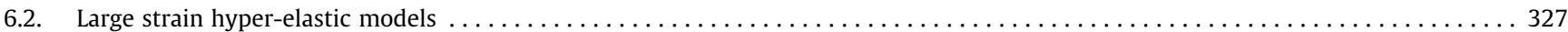

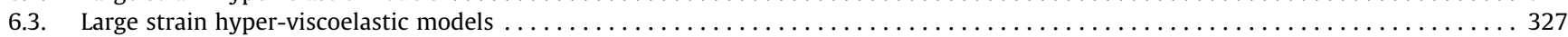

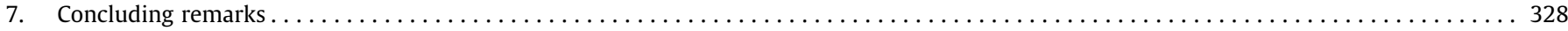

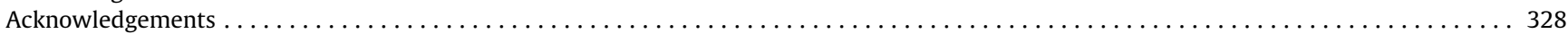

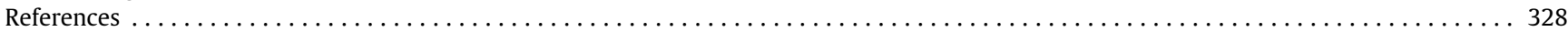

\section{Introduction}

Helmets have been used for head protection for centuries. The Sumerians, Assyrians, ancient Greeks, and Romans wore them throughout the middle ages. The Napoleonic era saw the introduction of ornate helmets, which continued to be used by the French army in World War I. However, these helmets provided very little protection against artillery shells. The French Adrian helmet was the first modern steel combat helmet. Steel helmets similar to the French Adrian helmet were soon adopted by other warring nations. The original World War I French and British helmet designs were adapted by the US Army to form the Hadfield steel helmet. The Hadfield helmet was eventually re-designed for lower weight, better comfort, and higher protection to produce the famous World War II M1 steel helmet (see Fig. 1) [150].

In the early 1960s, the US Army embarked on a program to replace the M1 steel helmet design with a single-walled, lighter, and more protective configuration. After considerable research and development efforts, the improved Personnel Armor System for Ground Troops (PASGT) combat helmet (made using Kevlar ${ }^{\circledR}$ fibers) replaced the steel M1 helmet. Since the PASGT helmet, the US Army has introduced two more kinds of combat helmets. The first is the Advanced Combat Helmet $(\mathrm{ACH})$, and the second is the lightweight helmet ( $\mathrm{LWH}$ ) of the US Marine Corps. These modern-era helmets have saved many lives and received great praise. Since their successful implementation, the trend for helmet development has been mainly towards weight reduction, and the concept of "a soldier as effective as a tank" (e.g., [16]) has become appealing to the Army. It has been envisioned that an advanced helmet should have a remote sight, a night vision device, a GPS, and a laser range finder to make an individual soldier a more effective fighter. Incorporating all these desired features in the helmet would require a radical change in the functionality and helmet design.

Improvised explosive devices (IEDs) have been increasingly used in recent conflicts, exposing soldiers to blast events. Blast induced traumatic brain injury (TBI) is the most prevalent injury in the Iraq and Afghanistan wars. Very little is known about the effectiveness of the $\mathrm{ACH}$ against a blast event and its subsequent influence on a human head. There have been a number of research initiatives to design a blast-resistant lightweight combat helmet. This article provides a comprehensive and critical review of existing studies in the topical area. Several key factors that affect the combat helmet performance, such as mechanisms of ballistic energy absorption, ergonomic aspects of ballistic helmet design, and material systems, are comparatively studied by analyzing published technical reports and research articles. In addition, recent experimental and computational studies performed to understand the complex injurious mechanisms of TBI and to develop constitutive models for brain tissues will also be critically examined.

\section{Ballistic helmets}

\subsection{Mechanisms of ballistic energy absorption}

The basic function of a combat helmet is to provide protection against shrapnel and ballistic threats. The ballistic performance of a material can be measured using the ballistic limit (e.g., [34]). For a given projectile, the ballistic limit is defined as the projectile velocity at which the projectile is expected to penetrate the armor/ helmet $50 \%$ of the time. Also, when a bullet strikes a helmet, a cone is formed on the back face of the helmet. The depth of this backface signature (a conical bulge) is required not to exceed a critical value. If the depth exceeds this value, the helmet shell can strike the skull, resulting in behind armor blunt trauma (BABT) (e.g., $[18,124,17,65,110])$.

Impact events are of three types (e.g., [98]): lower velocity impact, high velocity impact, and hyper-velocity impact. Low velocity impact is defined as an impact event where the time for the projectile in contact with the helmet exceeds the period of the lowest vibrational mode. In a low velocity impact event, the boundary conditions of the structural component are important in order to accurately describe the impact response. In a high velocity impact (ballistic or blast impact) event, the local material behavior in the
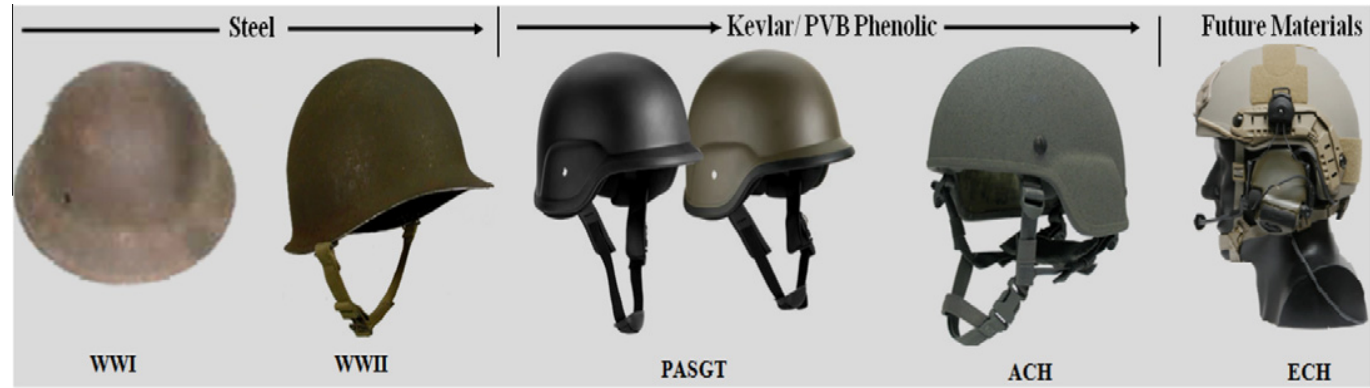

Fig. 1. Changing designs and materials of the US Army helmet from World War I to the latest headgear system [151]. 
impacted zone governs the impact response of the structure. In a hyper-velocity impact event, the locally impacted material behaves like a fluid and very high stresses are induced.

The PASGT and the ACH are made from ballistic fabrics $\left(\operatorname{Kevlar}^{\circledR}\right)$. Most ballistic fabrics exhibit a weave pattern formed by warp and weft yarns (e.g., [53,34,103]). When a woven fabric is impacted by a projectile, transverse and longitudinal waves are generated (e.g., [11]). These longitudinal and transverse waves travel along the yarns until they encounter an obstacle like a fabric edge or a fiber cross-over point. The waves are reflected at the obstacles and collide with the outward traveling waves. The kinetic energy carried by these stress waves is dissipated through a number of mechanisms, including cone formation on the helmet back face, deformation of secondary yarns, primary yarn breakage, inter-yarn friction, and friction between the projectile and the fabric (e.g., [58]). Shear plugging has also been observed as one energy dissipating mechanism [98]. As the strain within a fiber exceeds a critical value (called the dynamic tensile strain), the fiber fails. Each successive fabric layer absorbs the un-dissipated energy until the projectile is defeated. Failure of all fabric layers results in complete perforation. If the projectile velocity becomes zero before complete penetration, then the projectile has been successfully defeated.

\subsection{Effects of curvature}

The majority of research on ballistic performance has been conducted on flat laminates. However, the curvature given to a helmet during its manufacturing from flat laminates leads to stretching and shortening of fibers. Therefore, the ballistic response of a helmet to high velocity impact can be different from that of a flat panel laminate. A number of authors (e.g., $[146,67])$ have studied the effect of curvature on the impact resistance of a helmet. It was observed in van Hoof et al. [146] that the back-face deformation on a helmet induced by a projectile was greater than that on a flat panel fabricated from the same material. The curvature effect on the ballistic limit of a Kevlar helmet was investigated in Tham et al. [144], where the helmet was found to have a higher ballistic resistance than that of a Kevlar laminate.

Delamination is a major energy absorbing mechanism in ballistic impact. The effects of curvature on stresses generated in curved beams and delamination failures have been investigated in Nguyen [100], where finite element and analytical studies on graphiteepoxy curved beams were carried out for three different radii of curvature. It was found that the radial stress increases as the radius decreases. That is, the radial stress is the lowest for a flat beam that has an infinitely large radius of curvature.

All these studies indicate that reducing the radii of curvature of a helmet increases its ballistic impact resistance. However, a direct study comparing the ballistic impact resistance of a helmet changing with its radii of curvature has not yet been performed. Hence, both flat laminates and the actual helmet should be tested for their ballistic impact responses when a helmet is manufactured from new materials. It is also desirable to determine the optimal radii of curvature of a helmet (if existing) in order to maximize the ballistic protection.

\subsection{Performance measures of ballistic helmets}

An infantry soldier carries all his/her equipment. The duties of such a soldier are physically demanding, and any addition to the weight carried generates considerable impairment to the endurance of the soldier. Therefore, weight is a primary consideration in designing any new helmet system. In addition to weight, other criteria considered in a helmet design include the following [106]:
1. Ballistic performance - Ballistic protection is a primary consideration in the fielding of a new helmet. For example, for the World War II steel M1 helmet, the ballistic performance was measured by the helmet's ability to defeat a pistol ball traveling at a certain velocity [16]. The ballistic performance of a composite helmet depends on the material used, helmet thickness, and fabrication method. A compromise often has to be made between the weight allowed and the ballistic protection requirements. Because of the use of improvised explosive devices (IEDs) in urban warfare, an infantry soldier is exposed to blast events with an increasing frequency $[123,19,118]$. Hence, it has become necessary to examine whether the current ballistic standards for a combat helmet are valid for new and emerging fighting environments.

2. Location of center of mass - The ideal location for any weight on the head is on the straight line connecting the center of mass (CM) of the head and the CM of the body. Any shift in the weight balance on the head from the natural CM of the head will result in straining and fatigue of neck muscles. It will also hinder the body balance during other movements like running, crouching, jogging, or walking, because of muscular accommodations required [115]. The force exerted on the skull base is the acceleration multiplied by the mass of the helmeted head (in case of impact). The magnitude of the center of gravity (CG) offset torque is proportional to the CG offset distance, acceleration, and helmet/head mass. Therefore, it is important to have the smallest possible offset distance between the CG of the helmet and the CG of the head.

3. Maintenance of head movement - An infantry soldier must be able to scan his/her surroundings for any sign of threats or targets. This implies that there should be no impairment of the head-neck movement. In addition, vision and hearing should be maintained. Particular care should be taken of any attachment on the helmet. Any new attachment should enhance the vision and hearing of a soldier rather than impairing it. It is necessary to test the new helmet in field settings before implementing it. There is a possibility that loose hanging wires or cables may entangle with other items/equipment pieces like guns, surrounding vegetation, field telephones, or gas masks.

4. Cost and user acceptance - Any helmet that is far too costly to implement will not be fielded. Other factors to consider are availability and cost of materials and ease of fabrication. A helmet that can be produced in large volumes at a reasonable cost has a better chance of being accepted. User acceptance depends on the actual fit of the helmet, comfort level, and benefits in actual combats. Engaging the end users in the development process as frequently as possible will increase the acceptance possibility. Any additional attachments to the combat helmet should be easily removable by the soldier. If the benefits of a new helmet for mission completion and survivability are evident to a soldier, some additional weight or discomfort may be tolerated.

5. Helmet sizing and fit - Modern-day helmets are designed to provide much more than just ballistic protection. If the fit of the helmet were not comfortable, the helmet user would be reluctant to wear it. The fit of the protective head gear thus affects the performance of the soldier. Fit of an item depends on the anthropometry. Traditionally, there have been two ways for determining the size and fit: (a) starting with a basic size and using grade rules to predict higher sizes, and (b) anthropometric sizing [120]. However, both of these methods have drawbacks and could lead to designs with incorrect sizes and wrong anthropometric fit regions. Traditional anthropometric methods account for the head circumference variation, but do not consider the variation in head curvature. There are many examples of uncomfortable and bulky helmet designs that do 
not accommodate the entire range of users. The recent development of 3-D scanning technology has opened up new opportunities for creating more accurate human head models for design, evaluation, and optimization of helmet fit. New techniques have been developed to acquire and analyze helmet fit data. 3-D laser scanning has been used for a representative sample population to establish a helmet sizing criterion [64]. The standoff distance (gap between the head and the helmet) was fixed as $12.5 \mathrm{~mm}$. Based on the head length and breadth, the population was divided into groups with medium, large, and extra-large head sizes. 3-D laser scanning technology coupled with Fourier transforms was used to measure 3-D surface dimensions of a head [64]. 3-D coordinates of the head were extracted from MRI scans and stored as data points. This resulted in considerable data saving, compared to storage of MRI scan images for all the samples. The boundary of the head surface was then fit by Fourier transforms. The coefficients of the Fourier transforms replaced the data points. The coefficient values differ for different head sizes. Finally, all the samples taken were divided into nine standard head forms based on the head breadth and height. In another work, the variations in the shape and size of a Chinese male/female head were studied and a methodology of creating a homologous head/face model was developed [161]. By using 3-D laser scanning, 3-D head information was collected for 144 participants (72 male and 72 female). The data were processed and aligned, and landmarks (virtual and anatomical) were chosen on the head and the face. In order to generate a homologous head/face model, the Delaunay triangulation was carried out based on the landmarks selected. A symmetric mesh was generated for the left and right sides of the face. Principal component analysis (PCA) was carried out separately for a male head and a female head to find the largest varying dimension amongst individuals. After the PCA analysis, average male and female head models were developed. Based on the calculated head width, height and depth for the samples, it was found that the changes in the head width and depth are larger than the change in the head height. The same trend was observed for both the males and the females. This study provided a methodology to convert the raw data obtained from 3-D head scanning to a 3-D homologous head model. Traditional anthropometric methods have been unable to create helmet sizes that fit the entire range of users. Proper helmet size, fit, and stability are critical to personnel safety. If the helmet sits too low on the head, it interferes with the line of vision. If the helmet sits too high, the risk of injury increases. If it is too tight or too loose, the helmet can be a constant bother. The use of advanced helmet development processes (such as 3-D laser scanning, computer aided design, new surface generation software, and stereo lithography) for helmet sizing can enhance the comfort level for the end user. Greater accuracy and design control can be obtained through better fitting, thereby reducing the number of sizes, inventory, and logistical costs and enhancing helmet performance and acceptance.

\section{Conventional material systems}

\subsection{Personnel Armor System for Ground Troops}

The first combat helmet was the French Adrian steel helmet. This was adopted by other nations including the US to form the Hadfield helmet, which was used during the First World War. The Hadfield helmet was re-designed for better comfort and protection to produce the M1 helmet. The M1 helmet was the longest serving helmet. The M1 helmet could defeat a pistol shot fired at a certain velocity, as required by the ballistic criterion imposed then
[16]. However, the M1 helmet was manufactured in only one size (e.g., [79]). In addition, it retained heat, did not protect the temporal area, and had to be removed before using tele-communication devices. To mitigate these difficulties, the New Helmet Design Program was initiated in 1972. Composites had already been developed by that time, with the Kevlar ${ }^{\circledR}$ fibers developed in 1965. This program led to the development of the new Kevlar ${ }^{\circledR}$ fiberbased Personnel Armor System for Ground Troops (PASGT) helmet [150], which overcame the drawbacks of the M1 helmet and replaced the M1 steel helmet in the 1980s. The PASGT helmet was manufactured in four sizes, had improved ventilation, and covered a larger part of the head. The shell was made of layers of Kevlar ${ }^{\circledR}$ K29 fibers and offered protection against 0.22 caliber, Type 2 fragment simulating projectile. The V50 ballistic limit for the PASGT helmet was required to be not less than $610 \mathrm{~m} / \mathrm{s}$ [144]. The PASGT helmet was in service for 20 years and demonstrated great field durability. However, with its standard $9 \mathrm{~mm}$ thickness shell, it barely met the operational needs. The PASGT helmet also had fitting problems.

\subsection{Modular Integrated Communications Helmet and Advanced Combat Helmet}

With an aim to reduce the weight of the PASGT helmet, the US Army launched a new helmet development program. Two new helmets were introduced, namely the Modular Integrated Communications Helmet $(\mathrm{MICH})$ and the Advanced Combat Helmet $(\mathrm{ACH})$.

The MICH utilizes $\operatorname{Kevlar}^{\circledR}$ fibers and provides less coverage than the PASGT helmet. However, this causes less vision obstruction for the wearer and combines well with the interceptor body armor. For the PASGT helmet, the high collar of the interceptor body armor pushed the helmet forward, thus obstructing vision in prone position.

The ACH, derived from the MICH, is made from the Kevlar ${ }^{\circledR}$ K129 fiber. The Kevlar ${ }^{\circledR}$ K129 fiber has an areal density of around $185 \mathrm{~g} / \mathrm{m}^{2}$ compared to $270 \mathrm{~g} / \mathrm{m}^{2}$ for the Kevlar ${ }^{\circledR} \mathrm{K} 29 \mathrm{fi}-$ ber, but has a strength which is $40 \%$ higher than that of the Kev$\operatorname{lar}^{\circledR}$ K29 fiber (used for the PASGT helmet). The Kevlar ${ }^{\circledR}$ K129 fiber also has a higher energy absorption capacity than the Kev$\operatorname{lar}^{\circledR}$ K29 fiber [12]. The ACH thus has a higher ballistic and impact protection capability than the PASGT helmet at a smaller weight.

The ACH also has a pad system inside the helmet, replacing the nylon cord suspension system used in the PASGT helmet. This provides a better fit to the wearer and can give a higher protection against blunt trauma in case of ballistic impact (e.g., [1,96]). Recently, a survey on soldiers' satisfaction with ballistic helmets was conducted by Ivins et al. [72]. The survey indicated a strong preference of the soldiers for the ACH over the PASGT helmet. The survey also identified some problems with the ACH. Table 1 lists a brief summary of the survey.

Table 1

Comparison of the ACH helmet with the PASGT helmet [72].

\begin{tabular}{lll}
\hline Problem type & $\begin{array}{l}\text { Percentage of } \\
\text { all ACH users } \\
(n=535)\end{array}$ & $\begin{array}{l}\text { Percentage of } \\
\text { all PASGT users } \\
(n=570)\end{array}$ \\
\hline Loose screws & 11 & 1.8 \\
Loose/broken straps & 5.8 & 3.7 \\
Hard/loose pads & 4.1 & No padding \\
Heat retention & 1.5 & 0.9 \\
Poor fit & 0.6 & 4 \\
Falls from head & 0.6 & 0.7 \\
Weight satisfaction & 84.7 & 6.4 \\
Other & 1.1 & 1.8 \\
\hline
\end{tabular}




\section{Modern material systems}

\subsection{Polymers}

There are many factors that control the response of a material to ballistic impact. However, the main source of kinetic energy absorption is the straining and breakage of primary and secondary fibers. Therefore, the stress-strain curve and the fiber tensile strength play a major role in predicting the impact response of a ballistic fiber. Table 2 shows the tensile properties for various armor-grade fibers. Kevlar ${ }^{\circledR}$ fibers, variants of a rigid rod liquid crystalline synthetic polymer fiber developed by DuPont in 1965, have been used in most modern body armor systems. The PASGT helmet uses the Kevlar ${ }^{\circledR} \mathrm{K} 29$ fiber. The ACH, which was fielded in 2003 to replace the PASGT helmet, uses the Kevlar ${ }^{\circledR}$ K129 fiber and provides an improvement in ballistic performance and user interface. The new padding system inside the $\mathrm{ACH}$ affords better comfort and higher protection. Like the PASGT helmet, the ACH utilizes a thermoset resin shell (as the matrix material) bonded to Kevlar ${ }^{\circledR} \mathrm{K} 129$ fibers.

Thermoplastic resin shells have been considered as an alternative to thermoset resin shells. Thermoplastic resins are sufficiently tough and chemical resistant. Thermoplastics are also melt-processable. It has been shown that the elasticity of a matrix greatly affects the energy absorption capacity of a composite. A rigid matrix reduces the ballistic performance as compared to a flexible matrix [45]. However, thermoplastics have lower tensile strength than thermoset resins. This has an adverse effect on the structural stability and the transient deformation characteristics of the helmet. Thermoplastics (as matrix materials) are therefore used with fibers having a higher tensile modulus than the Kevlar ${ }^{\circledR}$ fibers to augment the matrix stiffness.

Thermoplastics for ballistic applications have been studied extensively $[12,150,151]$. Both manufacturing and design aspects of thermoplastics were investigated in Walsh et al. [150,151], where various $\operatorname{Kevlar}^{\circledR}$ fiber-thermoplastic matrix systems were explored. The weight was the primary consideration in preparing the samples. An increase in ballistic resistance was obtained at a much lower weight. However, the depth of the back-face signature increased considerably compared to that for a thermoset resin based helmet, thus increasing the possibility of blunt trauma injury. A detailed study of thermoplastics for ballistic applications was conducted in Song [132], where semi-crystalline and amorphous polymer matrices were examined. The materials used for the samples were $\mathrm{Kevlar}^{\circledR} \mathrm{K} 29$ fiber/nylon 66 matrix laminates, Kevlar $^{\circledR}$ K29 fiber/polyetheretherketone (PEEK) matrix laminates, Kevlar $^{\circledR}{ }^{\circledR}$ K29 fiber/polycarbonate matrix laminates, Kevlar ${ }^{\circledR}$ K29 fiber/polysulfone matrix laminates, Kevlar ${ }^{\circledR}$ KM2 fiber/polysulfone matrix laminates, and $\operatorname{Kevlar}^{\circledR} \mathrm{KM} 2$ fiber/linear low-density polyethylene (LLDPE) matrix laminates. The effects of processing temperature, cooling rate, polymer morphology, fiber-wetting characteristics, reinforcing fabric configuration, and composite stiffness on the ballistic impact resistance of thermoplastic-based

Table 2

Tensile properties for various fibers $[12,34,132]$.

\begin{tabular}{lllll}
\hline Material & \multicolumn{2}{l}{ Properties } & & \\
\cline { 2 - 5 } & $\begin{array}{l}\text { Density } \\
\left(\mathrm{g} / \mathrm{cm}^{3}\right)\end{array}$ & $\begin{array}{l}\text { Breaking } \\
\text { strain }(\%)\end{array}$ & $\begin{array}{l}\text { Tensile } \\
\text { strength (MPa) }\end{array}$ & $\begin{array}{l}\text { Tensile } \\
\text { modulus (GPa) }\end{array}$ \\
\hline Nylon $66^{6}$ & 1.14 & 18.2 & 1006 & 5 \\
Kevlar $^{\circledR}$ K29 & 1.44 & 3.5 & 2794 & 67 \\
Kevlar $^{\circledR}$ K129 & 1.44 & 3.3 & 3429 & 96 \\
PBO & 1.58 & 3.8 & 7386 & 195 \\
Spectra 1000 & 0.97 & 2.7 & 2995 & 172 \\
Dyneema $^{\circledR}$ & 0.97 & 3.8 & 2500 & 120 \\
\hline
\end{tabular}

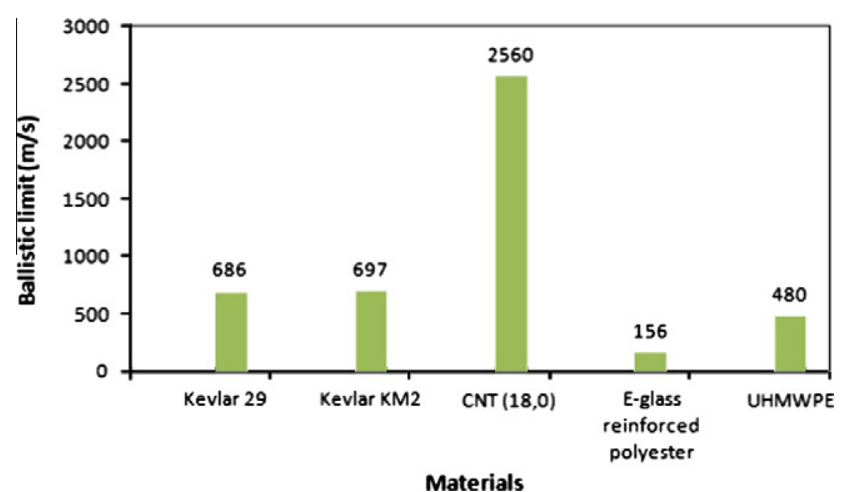

Fig. 2. Ballistic limits for various materials (e.g., [34,132]). The value for the CNT was based on molecular dynamics simulations [97].

composites were investigated in Song [132]. The main energy absorbing mechanisms identified for the laminated composites were fiber failure in tension, matrix cracking, and delamination. Processing temperature had a significant effect on the ballistic performance of amorphous and low crystalline polymer composites. Increasing processing temperature improved the wet-ability, leading to dense packing of the matrix molecules. This resulted in a stiffer matrix, diminishing the energy absorption capacity. For semi-crystalline polymer composites, processing temperature changes the nature of the crystals formed. However, this was found to have very little effects on ballistic properties.

Fabric configuration also has a significant influence on ballistic properties (e.g., [26,34]).

The Enhanced Combat Helmet (ECH), which has been under development since 2007 for the US Marine Corps and US Army, makes use of the Dyneema ${ }^{\circledR} \mathrm{HB} 80$ unidirectional composite material, which consists of a matrix of ultra high molecular weight polyethylene (UHMWPE) reinforced by carbon fibers (e.g., [160]). The values of the ballistic limit for UHMWPE and several other materials are shown in Fig. 2.

The weathering and gamma radiation effects on ballistic properties of UHMWPE composite armor have been studied in Alves et al. [3]. The composite plates were subjected to weathering (2 and 4 months) and gamma irradiation (25 kGy and $250 \mathrm{kGy}$ ). The plates were then tested for hardness, Charpy impact, flexure, and ballistic limit. The ballistic impact testing was carried out for a standard $9.0 \mathrm{~mm} 8$-g full metal jacket (FMJ) bullet. It was found that exposure to weathering for 4 months did not cause significant changes in the ballistic impact resistance. However, it significantly increased delamination failures in the plate under a projectile impact. This was attributed to oxygen diffusion between the layers, reducing the interfacial resistance. Also, it was observed that exposure to gamma radiation reduced the ballistic resistance. The higher the gamma radiation dosage was, the larger the local damaged area was. This is shown in Table 3. It was concluded that exposure to weathering and gamma radiation induces modification in the

Table 3

Increase in damaged area of the UHMWPE composite armor with weathering and gamma irradiation [3]

\begin{tabular}{lc}
\hline Condition of composite & $\begin{array}{l}\text { Average damaged } \\
\text { area of ballistic impact }\left(\mathrm{cm}^{2}\right)\end{array}$ \\
\hline As received & 6.25 \\
Weathered for 2 months & 7.12 \\
Weathered for 4 months & 7.69 \\
Gamma irradiation of $25 \mathrm{kGy}$ & 8.65 \\
Gamma irradiation of $250 \mathrm{kGy}$ & 40.77 \\
\hline
\end{tabular}


UHMWPE molecular structure, leading to changes in the mechanical and ballistic properties of the composite. It is therefore necessary to test the UHMWPE based helmet periodically to ensure that weathering and gamma radiation do not compromise the ballistic impact resistance of the helmet.

\subsection{Nanomaterials}

Carbon nanotubes (CNTs) are one allotrope of carbon, which have tubular structures, nanometer diameters, and large lengthto-diameter ratios. The mechanical, electrical, optical, and chemical properties of CNTs have been studied in detail (e.g., $[101,51,52,109,97])$. CNTs have high strength, lightweight, and good energy absorption capacity. It can be seen from Fig. 2 that the ballistic limit of CNTs (based on molecular dynamics simulations) is considerably higher than that of any material currently used for making ballistic helmets. Therefore, polymer matrix nano-composites, where a polymer matrix is reinforced by nanoparticles like CNTs (e.g., [52,80]), can be good candidate materials for ballistic applications. The most commonly used nano-particles and polymer matrices are listed in Table 4.

Mechanical properties, energy absorption capabilities, and bonding mechanisms of polymer matrix nano-composites have been extensively investigated (e.g., [125,55,137]).

Material properties related to energy absorption capabilities of nano-composites include particle stiffness, particle geometry, volume fraction, inter-particle distance, particle size, interfacial adhesion, particle size variation, and matrix strength [137]. It has been shown [41] that the optimum nano-particle size for ballistic energy absorption should satisfy two criteria: (a) It should be smaller than the critical size for polymer fracture; (b) it should have a debonding stress smaller than the polymer yield strength. Increasing the volume fraction of nano-fillers can increase both the toughness and modulus [112]. The matrix material also has a significant effect on the modulus and toughness of a nano-composite. Some polymer materials may not bond well with nano-fillers, causing a decrease in mechanical properties. It was reported [137] that CNTs, organclay, titanium oxide, aluminum oxide, calcium carbonate, silica, and silicon carbide are good nano-fillers for improving the energy absorption of polymer matrix nano-composites. Pre-dominant energy absorption mechanisms in fabric-reinforced polymer matrix composites are breakage of primary and secondary yarns, delamination, and shear plugging. However, for nano-scale reinforcements, some of these factors for energy absorption and dissipation are not relevant [137]. Debonding and particle fracture are important mechanisms in kinetic energy absorption in polymer matrix nano-composites [24]. It has been shown [156] that energy absorption by fiber pullout and by fiber fracture is more for a set of nano-particles than for a corresponding macro fiber. Another energy absorption mechanism is the bond formation and interfacial forces $[164,80,6]$ between nano-particles and a polymer matrix. When the nano-particles are of molecular size, covalent and van der Waals bonds are formed between the particles and the matrix [7]. This increases the shear strength and the adhesion force, thereby increasing the energy required for debonding. In contrast, the bonding energy between a single macro fiber and a polymer matrix is only due to van der Waals or electrostatic forces. In addition, if a

Table 4

Common polymer matrix and nano-scale reinforcement materials [125].

\begin{tabular}{ll}
\hline Polymer matrix & Nano-particle reinforcement \\
\hline Nylon & Titanium oxide \\
Polyolefins & Fumed silica \\
Epoxy resins & Nano-clays \\
Polyurethane & Carbon nano-fibers \\
Polyethylene & Carbon nanotubes \\
\hline
\end{tabular}

nano-particle is surface treated, an interphase is formed between the particle and the matrix. Interfacial properties are different from those of the constituent materials and add to the debonding energy [80]. Surface morphology also has an effect on energy absorption and dissipation characteristics (e.g., $[165,74])$. The nature of a matrix material has a significant effect on the bonding between a nano-particle and the matrix (e.g., [59,42]). Different matrix materials provide different ballistic impact resistance for the same nano-particles, and the same matrix material and different nanoparticles produce significantly different energy dissipation characteristics. Nano-particle dispersion within a polymer matrix also has an effect on the ballistic properties of the resulting nano-composite. Depending on the inter-particle distance, nano-composites can be classified as clustered, exfoliated, and intercalated. However, there has been no consensus (e.g., [153]) amongst researchers on the best dispersion method for highest ballistic resistance. In addition to the above-mentioned mechanisms, other energy dissipating mechanisms in nano-composites include crack pinning, crack deflection, debonding, void nucleation, shear banding, and micro-cracks.

Experimental studies have been conducted to understand ballistic resistance of nano-composites. Ma et al. [86] performed ballistic and blast experiments on nanoclay reinforced nanocomposite armor. Each armor sample consisted of an aluminum back plate and a ceramic face plate. The face plate was a combination of ceramic pellets and gluing polymer. The gluing polymer used was either pure epoxy or nanoclay reinforced epoxy. Two types of projectiles were employed in the ballistic testing - armor piercing M2 (APM2) bullets and armor-piercing incendiary full metal jacket (B32) rounds. Each armor sample was shot first by APM2 bullets and then followed by B32 rounds. It was found that the face plate containing nanoclay particles maintained its integrity even after two bullet hits, in contrast to the face plate made of pure epoxy. Each armor sample was also subjected to 600 psi air blasts. The maximum deflection for the pure epoxy resin face plate was $5.1 \mathrm{~mm}$ compared to $2.9 \mathrm{~mm}$ for the nanoclay reinforced face plate. More recently, Laurenzi et al. [81] performed experiments to study impact resistance of nanostructured composite materials reinforced with multi-walled CNTs. The ballistic panels were made from Kevlar ${ }^{\circledR}$ K29 fiber reinforced epoxy matrix nano-composites containing multi-walled CNTs (MWCNTs) with diameters 20$30 \mathrm{~nm}$ and lengths $10-30 \mu \mathrm{m}$. The samples were tested using Charpy impact tests. A $44 \%$ increase in energy absorption capacity was obtained for the composite containing $0.1 \mathrm{wt} \%$ MWCNTs, and a 56\% increase for the composite with $0.5 \mathrm{wt} \%$ MWCNTs. For the composite containing $1 \mathrm{wt} \%$ MWCNTs, no change in impact resistance was observed, indicating a MWCNTs concentration threshold between $0.5 \mathrm{wt} \%$ and $1 \mathrm{wt} \%$. These impact tests indicate that MWCNTs can significantly improve the ballistic properties of the Kevlar ${ }^{\circledR}$ K29 fiber-epoxy composite laminates.

Mutiscale simulations have also been performed to model dynamic responses of nano-composites under impact and blast loading. Using a multiscale method known as molecular structural mechanics (e.g., [84,52]), Rafiee and Moghadam [113] studied the impact and post impact behaviors of a carbon nanotube (CNT) reinforced polymer matrix composite based on a cylindrical representative volume element (RVE) consisting of a single walled CNT embedded in a polymer resin matrix. Each $\mathrm{C}-\mathrm{C}$ bond in the lattice structure of CNT was modeled using an equivalent 3-D beam element. A volume fraction of 5\% for the CNT in the RVE was considered. The CNT was simulated at the nanometer scale, while the polymer resin matrix was modeled at the micron scale. The interphase region between the polymer matrix and CNT was treated as a non-bonded interaction and was modeled using van der Waals forces. The van der Waals interactions between the carbon atoms in the CNT and the nodes of the inner surface of the resin matrix 
were modeled using 3-D non-linear spring elements. The properties of the non-linear spring elements were described by the Lennard-Jones (L-J) potential. Simulations were also carried out for a neat resin (not reinforced with any CNT) RVE. Axial impact loading was applied to one end of the cylinder, and zero displacement boundary conditions were imposed at the other end. The simulations showed that the maximum axial deflection of the neat resin was six times greater than that of the CNT reinforced composite. Also, the magnitude of the maximum tensile stress at the fixed end was higher for the neat resin case. The simulation results of Rafiee and Moghadam [113] revealed that even a small volume fraction of CNTs improves the impact resistance of the polymer matrix. Very recently, Volkova et al. [149] performed meso-scale simulations to study shock wave propagation in a SiC/Al nanocomposite reinforced with inorganic fullerene $\mathrm{WS}_{2}\left(\mathrm{IF}-\mathrm{WS}_{2}\right)$ nano-particles. A statistical volume element (SVE) with particles distributed randomly in the matrix was modeled. Simulations were conducted for three different configurations - IF-WS $\mathrm{W}_{2}$ nano-particles in an $\mathrm{Al}$ matrix, in a $\mathrm{SiC}$ matrix, and in a $\mathrm{SiC} / \mathrm{Al}$ composite. The effective properties of the SVE were obtained using the selfconsistent method of Budiansky [15]. The IF-WS 2 nano-particles were modeled as perfectly spherical and represented as a transversely isotropic material. The elastic constants for the IF-WS nano-particles were calculated using density functional theorybased MD simulations. A particle velocity was applied to one face of the SVE, zero displacement boundary conditions were imposed on the opposite face, and rolling boundary conditions were prescribed on the rest of the faces. The simulations revealed that stress propagates faster through the IF- $\mathrm{WS}_{2}$ particles than through the $\mathrm{Al}$ matrix. This leads to stress fingering and dispersion. These two effects are influenced by the volume fraction of the particles (inclusions), with stress fingering and dispersion increasing with the increase of the volume fraction of the inclusions. In addition, a greater mismatch in the moduli of the matrix and inclusions results in a greater degree of stress dispersion.

The main drawbacks of using nano-composites in ballistic applications are manufacturing difficulties and high cost. Costeffective production of nano-composites is still a topic of active research (e.g., $[78,114,92,94])$. The major methods for synthesis of carbon nanotubes are arc discharge, laser ablation, and chemical vapor deposition. Electro-spinning [117] and solution spinning [32] have also emerged as new methods for fabricating strong nano-fibers.

Although nano-composites, especially CNT-reinforced polymer matrix composites, are promising materials with several functional advantages, their manufacturing feasibility and cost effectiveness remain to be explored. The development of appropriate techniques for cost-effective fabrication of reinforcing nano-particles and their dispersion in matrix materials will decide whether such new nanostructured materials will be able to replace traditional and contemporary armor materials used in personal protection equipment, which include aluminum foams and elastomer-steel laminates (e.g., $[48,85,121])$.

\section{Traumatic brain injury (TBI)}

Traumatic brain injury (TBI), also known as intra-cranial injury, is a damage to the brain (see Fig. 3) induced by external mechanical forces, resulting in permanent or temporary impairment of the brain functions. Since Operation Enduring Freedom and Operation Iraqi Freedom, explosive devices have been responsible for many injuries of US soldiers. Improvised explosive devices, roadside bombs, and suicide car bombs have caused about 60\% of American casualties in Iraq and about 50\% in Afghanistan [158]. Among civilians, TBI can be caused by motor vehicle accidents, sports and work related accidents, and terrorist bombings. Because of its high economic impact on the society and families of the affected, TBI is also an important social problem. Traumatic brain injury caused by blast is called blast-induced traumatic brain injury (BTBI).

\subsection{Mechanism of blast}

A blast wave is generated from an explosion by sudden release of a large amount of energy in a very small volume (see Fig. 4). A blast wave usually consists of a shock wave and a blast wind [30]. Nonlinear physics that explains shock waves is also used to describe blast waves $[140,141]$. A wave can propagate in a medium with the speed of sound. The speed of sound depends on the temperature and pressure of the medium. If the pressure or temperature increases, the speed of sound also increases. A shock wave travels at a supersonic speed relative to the undisturbed medium. The arrival of a shock wave results in a sudden local rise of pressure, density, and temperature in the medium. Explosion usually results from a chemical reaction. When the detonation of an explosive material occurs, a hot high-pressure volume of gas is created, which is surrounded by a thin hot layer of air. This volume of gas expands as the shock wave. The surrounding air is accelerated by this expanding shock wave and propagates at a very high velocity, which forms the blast wind. An observer exposed to an explosion will be first subjected to the high-pressure shock wave and then to the high-speed blast wind. In a closed environment, the blast wave interacts with the surrounding structure, changing its characteristics and creating multiple wave reflections. Even in openfield conditions, the blast wave reflects from the ground, resulting in an increase in the blast pressure. With the blast wind being highly non-linear, it is difficult to predict the exact characteristics of the reflected waves. However, reflected waves significantly increase the blast pressure and the speed of the blast wind. Depending on the locations, an observer may be subjected to a single blast wave or multiple blast waves. For an observer far away from the blast site, the wave might consist of only reflected components of the primary blast wave. It is probable that a person close to the explosion will have lesser injuries, as compared to someone farther away [30].

\subsection{Blast-induced traumatic brain injury - experimental models}

Numerous experimental and computational studies have been conducted to identify the potential mechanisms of blast-induced traumatic brain injury (BTBI).

In experimental studies, compressed air impact tests, shock tubes, blast tubes, and open-field explosion testing are typically used, and animals and human head models are employed. Table 5 gives a brief summary of various experimental models and the related observations. Various theories for TBI have been proposed [134]. Even though these theories have been suggested for direct impact injuries, they have a strong relevance to BTBI. The leading theories for TBI include the vibration theory, the liquor strike theory, the theory of inertial intracranial dislocation of the brain, the rotational acceleration theory [68], the theory of stereotactical phenomena [105], and the pressure gradient theory [57]

Based on existing experimental studies, the following causes have been identified for BTBI:

1. Primary blast injury is caused by the direct interaction of the high-pressure blast wave with the body. Several mechanisms have been suggested for this. One of them is the passage of the blast wave through the skull, with the skull absorbing very little incident pressure [19]. Impedance mismatch 

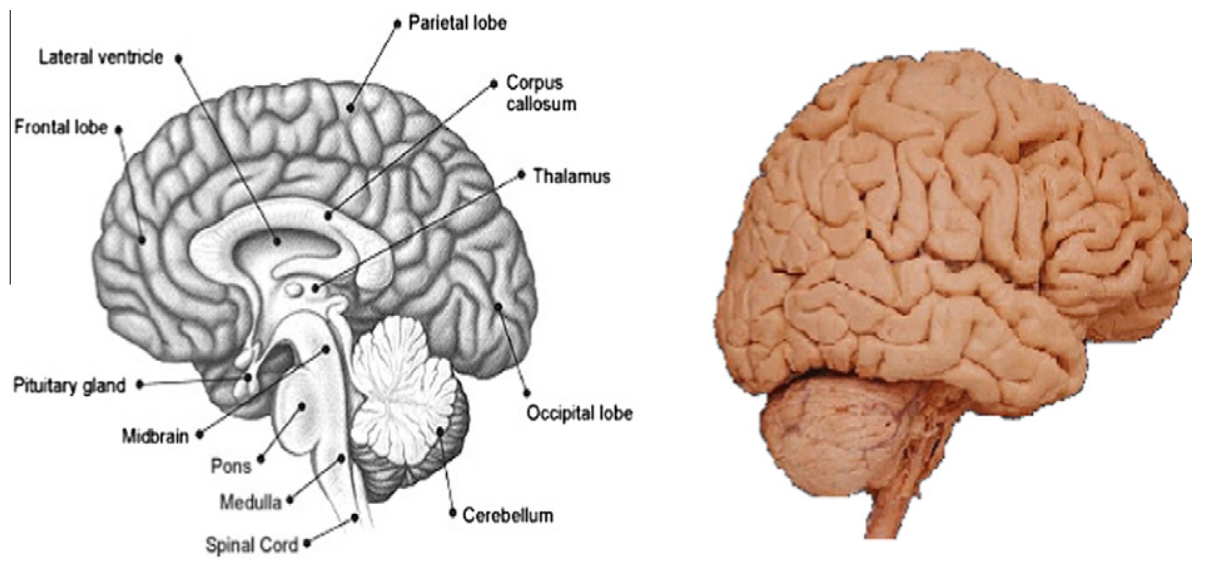

Fig. 3. Basic anatomy of human brain [145].

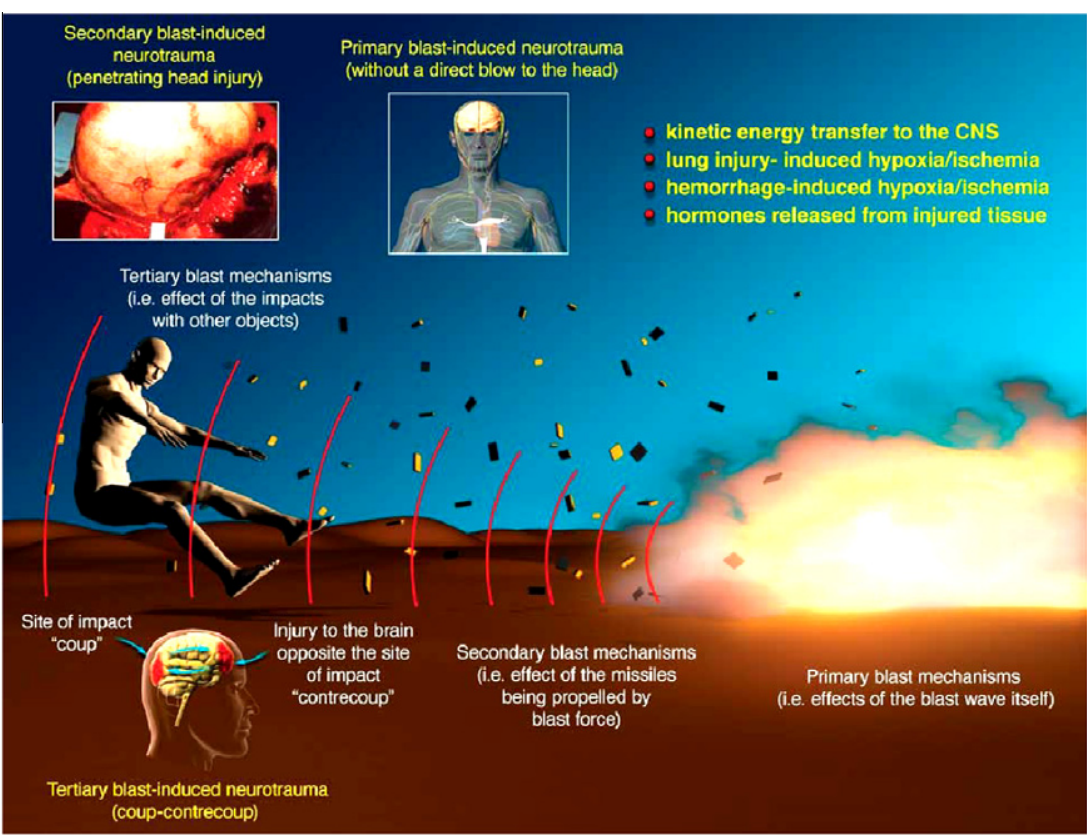

Fig. 4. Effect of blast waves on a human body [19].

between the skull material and air leads to considerable pressure amplification across the air-skull interface [2]. This suggests that blast overpressures far less than those required to cause immediate death could result in TBI. The mass difference between the skull and the brain tissue is another cause of TBI (as explained by the vibration theory and the inertial intracranial dislocation theory). Direct impact of the blast wave induces translational cranial motion. Since inertia of the skull is more than that of the brain, the skull stops vibrating before the brain. This gives reverse impact between the brain and the skull, leading to intracranial pressure changes. In the area opposite to the point of impact, negative pressure induces cavitation bubbles, which cause brain damage when collapsed. Such injuries are called tensile/compression injuries. Thoracic mechanisms have also been identified as possible causes of BTBI [29]. As the entire body is subjected to blast, the kinetic energy of the blast is transferred through the abdomen to the body's fluids. This initiates waves that deliver the kinetic energy to the brain. Multiple wave reflections are also causes of primary brain injuries.

2. Secondary blast injury is induced by the debris propelled by the high-speed blast wind. In case of terrorist bombings or IED explosions, there is a substantial probability of secondary injuries. In most cases, IEDs contain metal pieces, nails, glass, or ball bearings that are akin to bullet strikes. In addition, these shrapnels travel much farther than where the high pressure blast wave can go, increasing the probability of secondary injuries.

3. Tertiary blast injuries are predominantly caused by the acceleration of the body parts by the blast wind. Wind speeds in a Category four hurricane can reach around $210-249 \mathrm{~km} / \mathrm{h}$, while a blast wind can travel at around $2400 \mathrm{~km} / \mathrm{h}$ [130]. Any body part can be affected, but the head and the neck are particularly susceptible, because their acceleration differs from the rest of the body. In a rotational head motion, inertial forces are exerted on the brain, skull, and brain tissue. As the inertia of the skull is greater than that of the brain tissue, high shearing strains are generated in the intra-cranial region. These types of injuries are called "Diffuse Axonal Injuries" or shearing injuries.

4. Quaternary injuries are induced by the high temperature gases following the explosion. This may include burns and respiratory injuries caused by toxic gas inhalation. Permanent damage to the brain tissue may result because of excessive heating of the skull.

5. Besides traumatic brain injury, there are other physiological effects due to exposure to blast $[88,163,136,76]$. Exposure to blast causes compression of the thorax and abdomen because 
Table 5

Summary of important experiments carried out to study blast-induced neuro-trauma.

\begin{tabular}{|c|c|c|c|c|}
\hline $\begin{array}{l}\text { Type of } \\
\text { experiment }\end{array}$ & Explosive used & Model used & Finding & Author \\
\hline $\begin{array}{l}\text { Shock tube. } \\
\text { Pressure levels } \\
\text { below } 700 \mathrm{kPa}\end{array}$ & $\begin{array}{l}3 \mathrm{~g} \text { charges of pentaerythritol } \\
\text { tetranitrate (PETN) plastic } \\
\text { explosive. Laboratory standoff } \\
\text { distances at } 8-17 \text { in. }\end{array}$ & $\begin{array}{l}\text { Solid poly(methyl methacrylate) (PMMA) shell } \\
\text { skulls, PMMA shell skulls with features. Perma- } \\
\text { gel ballistic gelatin and polydimethylsiloxane } \\
\text { (PDMS) polymer to represent brain tissues. }\end{array}$ & $\begin{array}{l}\text { Impedance mismatch among air, PMMA skull } \\
\text { (bone matter) and gelatin (tissue) causes } \\
\text { considerable pressure amplification across the } \\
\text { air-skull interface. The curved surface of the } \\
\text { shell also induces pressure amplification. } \\
\text { Acceleration measurements revealed extreme } \\
\text { accelerations experienced on the interior face. } \\
\text { Shock waves transmitting into the tissue lead to } \\
\text { separation of tissue interfaces, creating } \\
\text { instantaneous vacuum. This results in an abrupt } \\
\text { material collapse, generating localized pressure } \\
\text { waves. }\end{array}$ & $\begin{array}{l}\text { Alley et al. } \\
{[2]}\end{array}$ \\
\hline $\begin{array}{l}\text { Shock tube. } \\
\text { Overpressures } \\
\text { ranged from } \\
600 \mathrm{kPa} \text { to } \\
8000 \mathrm{kPa} \text { used }\end{array}$ & Shockwave generator & $\begin{array}{l}\text { Head consisted of polyurethane skull and PDMS } \\
\text { skin. Head was attached to a flexible neck } \\
\text { structure. Cerebrospinal fluid (CSF) was } \\
\text { modeled as water. Additive gel mixed with } \\
\text { silicone gels was used to simulate brain matter. } \\
\text { This work mainly focuses on the } \\
\text { instrumentation and calibration }\end{array}$ & $\begin{array}{l}\text { Large pressure build-up was found within the } \\
\text { skull, particularly at the center. A shock wave } \\
\text { that is planar at the time of impact becomes } \\
\text { non-planar at the time of entry. }\end{array}$ & $\begin{array}{l}\text { Sogbesan } \\
{[131]}\end{array}$ \\
\hline $\begin{array}{l}\text { Blast tube. Blast } \\
\text { overpressures } \\
\text { from } 129 \mathrm{kPa} \\
\text { to } 769 \mathrm{kPa}\end{array}$ & $\begin{array}{l}1.3-3.0 \mathrm{~g} \text { of PETN plastic } \\
\text { explosive }\end{array}$ & $\begin{array}{l}3 \text { mm-thick ellipsoidal polycarbonate } \\
\text { transparent skull was used. Tissue matter was } \\
\text { Sylgard } 527 \text { gel. Six blasts were conducted with } \\
\text { various intensities, pressure, and orientations. }\end{array}$ & $\begin{array}{l}\text { A low level of strain was observed in the brain. } \\
\text { The amplitudes of both positive and negative } \\
\text { pressures inside the skull increased with the } \\
\text { blast intensity. The skull material was found to } \\
\text { absorb very little of the blast pressure. The } \\
\text { pressure-driven (rather than strain-driven) } \\
\text { injury mechanism was found to be responsible } \\
\text { for the brain trauma. }\end{array}$ & $\begin{array}{l}\text { Zhang } \\
\text { et al. [162] }\end{array}$ \\
\hline $\begin{array}{l}\text { Shock tube. Peak } \\
\text { pressure of } \\
42 \mathrm{kPa}\end{array}$ & Compressed air & $\begin{array}{l}\text { Rats were used in the study. A pressure probe } \\
\text { was placed inside each rat's brain. }\end{array}$ & $\begin{array}{l}\text { It was found that the skull absorbs very little } \\
\text { blast wave. }\end{array}$ & $\begin{array}{l}\text { Chavko } \\
\text { et al. [23] }\end{array}$ \\
\hline $\begin{array}{l}\text { Field study } \\
\text { conducted }\end{array}$ & $\begin{array}{l}5 \mathrm{~kg} \mathrm{C} 4 \text { charges placed at } 2 \text {, } \\
2.5 \text { and } 3.5 \mathrm{~m} \text { distances }\end{array}$ & $\begin{array}{l}\text { Mannequin for the assessment of blast } \\
\text { incapacitation and lethality (MABIL) made of } \\
\text { polyurethane was used. Three scenarios - 50\% } \\
\text { survivability, } 90 \% \text { survivability and lung } \\
\text { threshold - were tested for } 1 \text { ms and } 5 \mathrm{~ms} \\
\text { durations. Comparison was made based on the } \\
\text { mid-sternum acceleration and velocity. }\end{array}$ & $\begin{array}{l}\text { Contradictory results were obtained. The } \\
\text { shorter duration blasts generated a higher mid- } \\
\text { sternum acceleration, while the longer duration } \\
\text { led to a higher velocity. }\end{array}$ & $\begin{array}{l}\text { Bouamoul } \\
\text { et al. [13] }\end{array}$ \\
\hline $\begin{array}{l}\text { Open field, blast } \\
\text { tube, HMMVEE } \\
\text { surrogate and } \\
\text { building }\end{array}$ & Uncase explosive & Pigs & $\begin{array}{l}\text { Air overpressure was found to be the primary } \\
\text { cause of brain injury. Prominent brain injuries } \\
\text { were white matter fiber degeneration and } \\
\text { astrocytosis. }\end{array}$ & $\begin{array}{l}\text { Bauman } \\
\text { et al. [10] }\end{array}$ \\
\hline
\end{tabular}

of the presence of air-carrying organs [29]. This creates a surge in blood flow. When this increased volume of blood flow reaches the brain, it can lead to high pressures in the intra cranial region. It is therefore necessary to study this mechanical path from the abdomen to the brain. It has also been shown that an explosion creates a low-frequency electromagnetic field [83]. The effects of such an electromagnetic field on the brain and tissue have been recently studied in Lee et al. [83]. It was found that the bone piezoelectricity generates intense blastinduced electromagnetic fields in the brain. The strength of these generated fields is many times higher than that defined in the IEEE safety standards. These intense electromagnetic fields might be a potential mechanism of TBI. It is also well established that a prolonged exposure to high temperatures from the blast produces significant thermal effects. The skull is not able to dissipate a sufficient amount of heat, leading to a temperature increase in the tissue matter in the intra cranial region. The effect of the temperature increase on the tissue matter needs further investigations. Explosive detonation is a complex phenomenon. The nature of explosive, peak pressure, impulse, shape of the 3-D pressure distribution, temperature, velocity field, and structure frequency determine structural response to the blast. When the blast wave strikes a structure, the pressure loading is composed of two components: the pressure developed by slowing down the blast wind, and the pressure due to reflected waves. Studies conducted so far simulate only idealized pressure waves. An understanding of all damage mechanisms is vital for developing a headgear that can effectively protect against TBI.

As can be seen from Table 5, a very broad variety of methods has been used to inflict head injury. Field experiments have been predominantly conducted on pigs, rats, and mannequins. In almost all cases, animals are anesthetized and fixed in special holders. This prevents direct simulations of injuries caused by the blast wind component of the blast wave. Shock tube and blast tube experiments can only simulate idealized blast events. Therefore, comparing experimental results with clinical findings remains a challenging task.

\subsection{Blast-induced traumatic brain injury - numerical simulations}

A number of injury models have been proposed to capture brain responses to blast waves. Finite element methods have been widely used to model the damage to the body induced by blast waves. To model the motion and response of the body and its internal elements, the simulations usually begin with generating geometric models of varying complexity.

Three-dimensional (3-D) imaging data obtained from magnetic resonance imaging (MRI) or computed tomography (CT) 
techniques can be utilized to generate geometric models of various parts of a human head. In such image-based geometric modeling, suitably smooth surfaces representing brain tissues can be extracted from 3-D MRI or CT imaging data. Once the geometric model is created, standard tetrahedral or hexahedral meshing algorithms can be implemented for finite element (FE) mesh generation. Image based geometric modeling has been used by Ganpule et al. [49] for generating geometric models of skull, facial bones, neck bones, and brain tissues needed in their study on blast induced TBI.

Another popular approach is voxel meshing [75]. This method combines the surface detection and mesh creation stages in one process. In this approach, volumetric pixels (voxels) are divided into different regions using various segmentation techniques. These regions are then exported as hex elements. This algorithm is easy to implement, produces all hex mesh, and leads to conformity of mesh at interfaces. A 3-D FE human head model for studying brain trauma was proposed in Chen and Ostoja-Starzewski [25] using the voxel meshing technique. The FE mesh of their head model, consisting entirely of hexahedral elements, was developed from MRI data sets using a custom developed $\mathrm{C}++$ code. Five different tissue types - scalp, skull, CSF, gray mater, and white mater were identified from the MRI imaging data using a segmentation procedure. Voxel meshing was also employed by Taylor and Ford [142] to construct a head model based on the segmentation of high resolution photographic data using a pattern recognition algorithm.

A few commercial software packages that provide image based meshing capabilities are currently available, which include Amira (Mercury Systems, MA, USA), Mimics (Materialise, NJ, USA), Simpleware (Simpleware Ltd., UK), and Scan23D (Dassault Systèmes Solidworks Corp, Velizy, France). Mimics was used by El Sayed et al. [43] to reconstruct FE mesh from MRI data. The resulting mesh consisted of nine components - skull without facial bones, cerebrospinal fluid (CSF) in the form of a 3-mm thick layer, gray matter, white matter, cerebellum, corpus callosum, telencephalic nuclei, brain stem, and ventricles.

The effect of primary blast waves on the skull has been studied by Moore et al. [93]. The Bowen curve [14] was used to obtain a threshold of 5.2 atm for lung injury, a lethal dose of $18.6 \mathrm{~atm}$ for $50 \%$ lung injury was adopted, and the upper and lower bounds for survivable blast brain injury were established. In Nyein et al. [104], a FE model for an unprotected head was proposed using a mesh containing 808,766 elements (see Fig 5). The computational model distinguished different parts of the head: ventricle, glia, white matter, gray matter, eyes, venous sinus, cerebrospinal fluid (CSF), air sinus, muscle, skin and fat. The volumetric response of the brain tissue was described by the Tait equation of state, the deviatoric response by the neo-Hookean elasticity model, and the skull response by the Mie-Gruneisen/Hugoniot equation of state. Significantly different strain distributions were observed in different parts of the tissue material and brain. Based on the maximum compressive/tensile stress and von Mises stress in the brain, it was concluded that the blast intensity corresponding to $50 \%$ of the lethal lung injury caused mild traumatic brain injury (mTBI). In addition, direct blast propagation into the brain occurred with the skull absorbing very little or no pressure intensity.

A similar study was carried out by Grujicic et al. [61]. The comparison of the von Mises stress for three blast intensities showed that the stress values were not high enough to cause mTBI. However, direct passage of longitudinal and transverse pressure waves within the intra cranial cavity could lead to mTBI.

The effectiveness of the skull in protecting the brain from blast waves was studied by Teland [143]. A pig head model consisting of the skull, brain, and CSF was used. The material was assumed to be linearly elastic. It was found that the hard skull does not protect the brain from the blast waves. The pressure waves were not absorbed by the skull material but traveled through the skull to the brain.

Comparisons of brain responses to front and lateral impacts (see Fig. 6) have been studied by El Sayed et al. [43]. In their study, the load on the head was applied as a pressure wave rather than a direct blast. The pressure was applied as a semi-sinusoidal time distribution for six milliseconds (ms), with a peak magnitude of $7.90 \mathrm{kN}$. For the frontal impact, peak positive pressures were observed beneath the impact site, while negative pressures were observed in the area opposite to the impact site. Irreversible cavitation damage was also observed. However, no permanent shear damage was found. For the lateral impact simulations, the magnitudes of the coup and countercoup pressures developed were much higher. In addition, the magnitude of the shear stress developed was ten times higher than that in the frontal impact case, causing shear yielding. This showed that a lateral impact had a more damaging effect on the brain than a direct frontal impact.

A detailed head model was used in Chafi et al. [20] to predict the pressure distribution, shear stress distribution, and principal strain distribution in a brain subjected to a blast wave. The isotropic Mooney-Rivlin model was used to describe the hyper-elastic constitutive relation of the brain tissue material. The viscoelastic response is represented in terms of a convolution integral, and the relaxation modulus is described by a standard Prony series. The Jones-Wilkins-Lee equation of state (EOS) was used to model explosives, and the material parameters used in the EOS were those of trinitrotoluene (TNT). Three blast intensities corresponding to $0.0838,0.205$, and $0.5 \mathrm{lbs}$ of TNT were used at a fixed standoff distance. In the simulations, no uniform pressure gradient was observed across the brain tissue. In addition, the classical coup and countercoup pattern was not observed (unlike in other studies). Both positive and negative pressures were observed at the impact site as well as at the opposite side. Based on the Ward criterion [155], for the blast scenarios generated by $0.205 \mathrm{lb}$ and $0.5 \mathrm{lb}$ TNT, the average peak positive pressure exceeded the established thresholds. The brainstem, white matter, and corpus callosum experienced maximum shear stresses. At early stages of impact,
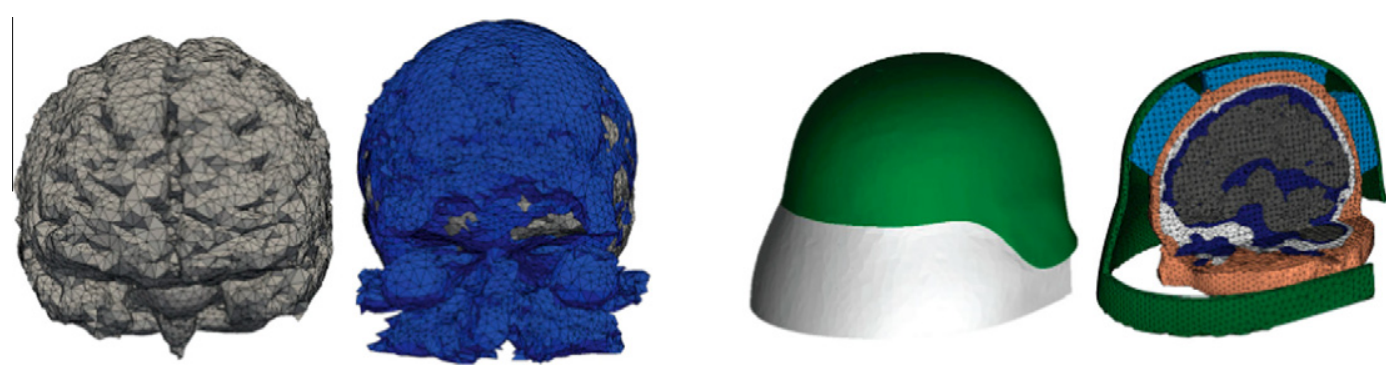

Fig. 5. A detailed head model [104]. 


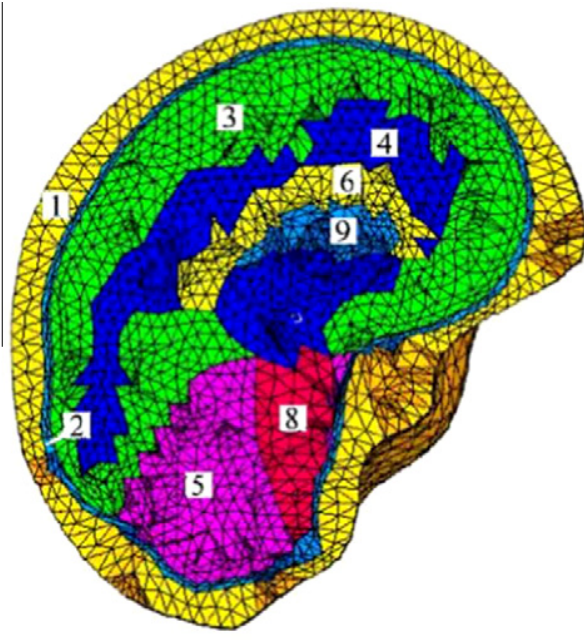

mid-sagittal

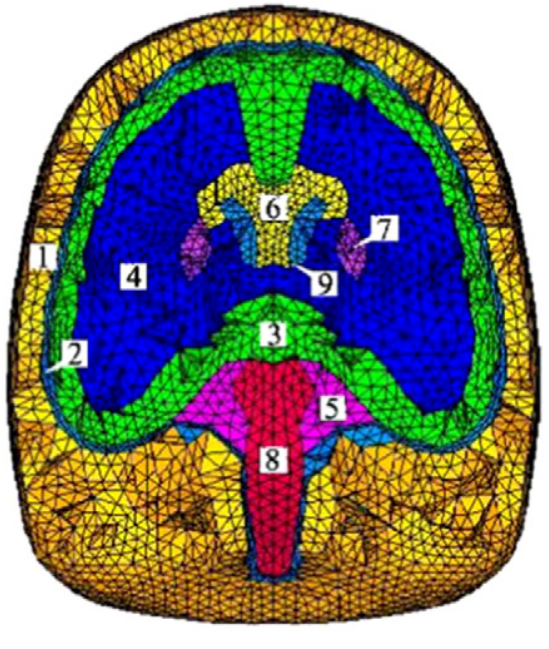

mid-coronal

Fig. 6. Head model used by El Sayed et al. [43].

the pressure intensities were higher than shear stress magnitudes. However, the stress magnitudes elevated after these early stages. The maximum principle strains were observed in the brainstem. According to the criterion of Bain and Meaney [8], for a blast scenario of $0.5 \mathrm{lb}$ explosive, the principal strain values exceeded the established threshold.

\subsection{Ballistic helmet and traumatic brain injury}

Traditionally, combat helmet design has been focused on providing protection against ballistic impact from projectiles. The Advanced Combat Helmet $(\mathrm{ACH})$ made from the Kevlar ${ }^{\circledR}$ fibers was designed to protect against shrapnel, fragmentation, and $9 \mathrm{~mm}$ bullet shots (see Fig. 7).

The response of a Kevlar ${ }^{\circledR}$ helmet to ballistic impacts was studied in Tham et al. [144]. It was found that a Kevlar ${ }^{\circledR}$ helmet could defeat a high-velocity $9 \mathrm{~mm}$ bullet and a $1.1 \mathrm{~g}$ fragment-simulating projectile (FSP).

There has been a recent interest in testing the effectiveness of the helmet against blast events and blunt trauma injuries. The response of a combat helmet to blast waves was studied by Moss et al. [96] by modeling the skull as a hollow elastic ellipsoid containing viscoelastic CSF and using a simplified face, neck and body system with no lower jaw. The head was subjected to a shock wave with an overpressure of one bar over the ambient pressure and a $450 \mathrm{~m} / \mathrm{s}$ blast wind. For an unprotected head, the skull wall deforms and collides with the brain. This develops large positive and negative pressure spikes in the cranial cavity. It also creates damaging shear strains. For a head protected with a helmet, the $1.3 \mathrm{~cm}$ gap between the helmet and the head creates an "underwash" effect. The gap allows the blast wave to wash in between the helmet and the head. This causes more pressure on the skull than in an unprotected head. For a helmet with padding, the helmet is coupled to the head and the underwash effect is mitigated. It should be mentioned that without including lower jaw and anatomical details (such as skull thickness variations, gray or white matter, and ventricles), the model adopted by Moss et al. [96] is overly simplified and needs to be validated, as also noted in Nyein et al. [104].

In a recent study $[49,50]$, it was observed that tight foam pads between a head and a helmet can eliminate the underwash effect and thus provide a better protection from blast.

The effect of an $\mathrm{ACH}$ and a conceptual face shield on stress wave propagation within the brain tissue following a blast has been
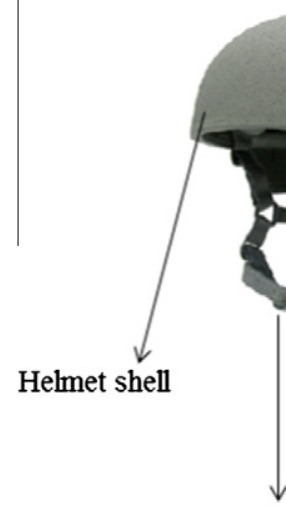

Chin strap (adjustable)

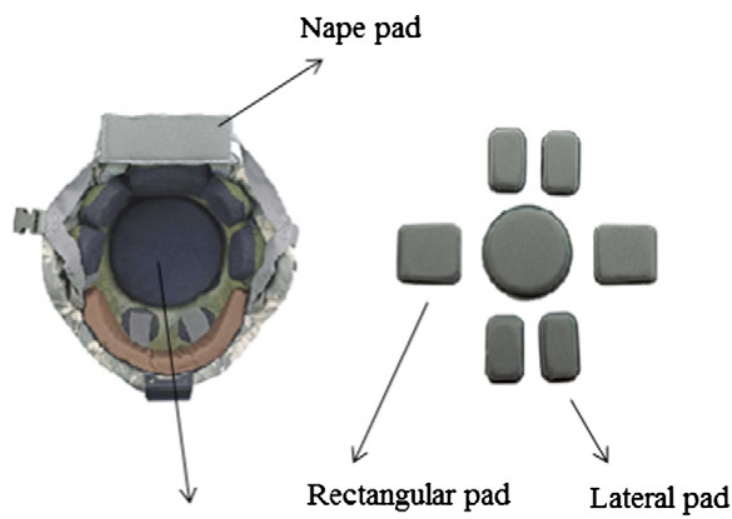

Crown pad

Slide adjustment

Fig. 7. $\mathrm{ACH}$ and its parts. 
studied in Nyein et al. [104]. A human head model was used along with a model of the $\mathrm{ACH}$ provided by the Natick Soldier Research Development and Engineering Center. The material models were the same as those used earlier in Moore et al. [93]. Simulations were carried out for an unprotected head, a head with a helmet, and a head with a helmet and a face shield. It was found that the main transmission pathway of the blast waves to the brain was through the soft tissues of the face. Tissue cavitation was also observed as a possible mechanism of brain damage. The simulation of a helmeted head with the current variant of the ACH showed that the helmet provides no mitigation of blast effects on the brain tissue, as it does not protect the face. The third simulation was carried out for a head with the $\mathrm{ACH}$ and with a conceptual face shield attached to it. It was observed that the presence of the face shield significantly contributed to reducing the stress intensity in the brain.

A similar study was carried out in Grujicic et al. [61]. The blast intensity and material models were taken to be the same as those used in Moore et al. [93]. Their simulations revealed that the blast wave propagates through the skull. It travels faster in the intra cranial cavity, and multiple reflections occur. Maximum compressive stresses were found on the impacted side, while the maximum tensile stresses were seen on the side opposite to the point of impact. Intra cranial shear stress values were substantially lower than those of the principle stresses. The maximum shear stresses were located in the brain stem. For both $5.2 \mathrm{~atm}$ and $18.6 \mathrm{~atm}$ blast intensities, no shear-induced mTBI was observed, while there was a possibility of contusion type TBI. For a head protected by a helmet, the findings obtained by Grujicic et al. [62] were contradictory to those reported in Moore et al. [93] and Nyein et al. [104]. For the helmeted head, the load transfer path to the skull was found to be different. The underwash effect observed in other simulations was also seen. However, for the helmeted head a $40 \%$ reduction in the maximum principal stress magnitude and an $8 \%$ reduction in the maximum shear stress magnitude were obtained. No mention was made regarding the propagation of blast waves through the soft tissue of the face. This is in contrast to the simulations reported by others (e.g., $[93,50])$, where the helmet either produced an increase in the pressure intensity on the skull or produced no significant reduction.

A comparative study on the blast wave mitigation capability of suspension pad materials has been conducted by Grujicic et al. [63]. The effects of blast waves on an unprotected head and a head protected with an $\mathrm{ACH}$ with polyurea as the suspension pad material were studied. In the absence of information about the currently used suspension pad material in the $\mathrm{ACH}$, Ethylene-Vinyl-Acetate (EVA) was chosen as a second material (other than polyurea). The material models and the pressure intensities were taken to be the same as those used in their earlier study [62]. High peak axial stresses and peak particle velocities were chosen as parameters for comparison. It was found that polyurea lowered the peak stresses and peak velocities transferred to the skull (and hence to the brain). Because these two are primary TBI causing mechanisms, it was concluded that polyurea was a better suspension pad material than EVA.

The Department of Defense's blast injury research program [135] and the non-lethal weapons human effects program under the guidance of the Air Force Research Laboratory [129] were initiated to conduct biomedical research in order to improve the current understanding of blast injuries. The goal of these programs is to characterize the complete hazard caused by the blast waves. The thoracic human body models used to study ballistic impact of armor and the human head models employed to investigate the physical effects of blast were combined to form the Advanced Total Body Model [129,135]. An integrated finite element model consisting of head, neck, thorax, and abdominal regions was employed to understand the mechanisms for BTBI.

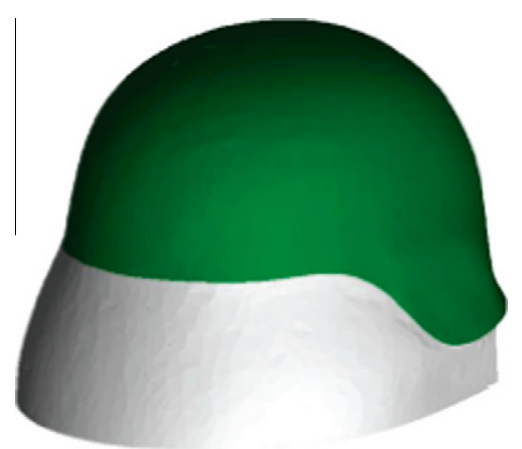

Fig. 8. Face shield and goggles suggested to improve blast mitigation capabilities of combat helmets [73]

A study on the effect of facial protective devices on injury mitigation in BTBI was conducted by Jason [73]. The head and material models employed in this study were the same as the ones used in Nyein et al. [104], and simulations were carried out for both the $\mathrm{ACH}$ and the ECH. The blast wave was generated by an explosion of $3.16 \mathrm{~g}$ of TNT in free air explosion at a $0.12 \mathrm{~m}$ standoff distance. The model validation was carried out by comparing the simulated results for a side blast with the experimental results obtained at the Naval Sea Systems Command Warfare Center (with experiments carried out on a series of mannequins) [104]. In order to reduce the effect of the blast waves traveling through the soft tissues of the face into the intra cranial cavity, a face shield (see Fig 8) was added to the helmet. The material of the face shield was the same as that of the helmet shell. The following simulations were carried out on: (a) an ACH with a face shield, (b) an ECH with a face shield, (c) an ACH with a pair of ski goggles, and (d) an $\mathrm{ECH}$ with a pair of ski goggles. The material model of the goggles was the same as that of the helmet shell. It was observed that the face shield prevents the direct transmission of the negative and positive pressure waves through the soft tissue of the face to the brain. The transfer of the pressure waves occurs through the foam padding. An undesirable effect of the face shield was also observed. There is a late increase in the pressure imposed on the surface of the face because of the air trapped between the face shield and the face. It was also observed that the unprotected region in the rear of the head causes an increase in the pressure exerted on the soft tissues of the face. It was proposed to extend the helmet shell to cover the neck. For the simulation with the goggles, it was observed that the goggles protect the soft tissue of the face. However, physical interaction between the goggles and the head offers a new pathway for pressure transmission. It was also observed that this secondary pathway reduces the pressure transmitted to the head through

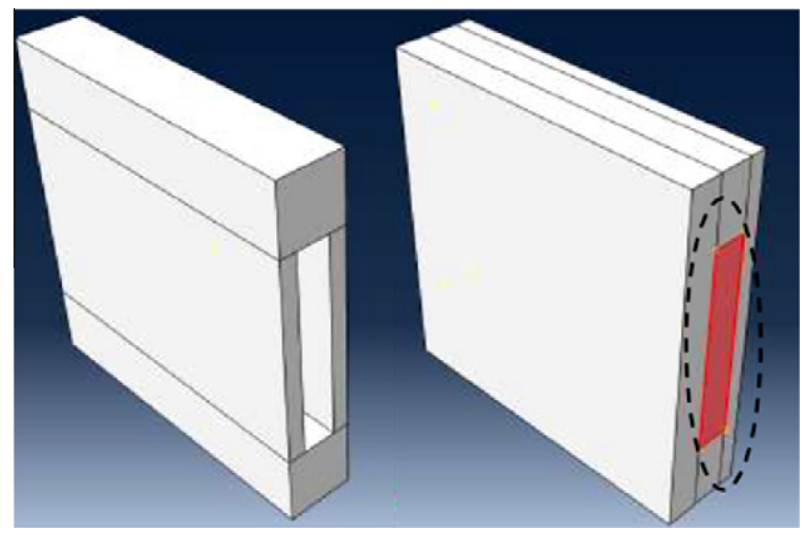

Fig. 9. Drilling channels in the liner of an $\mathrm{ACH}$ filled with an incompressible material [56]. 
the padding, i.e., it reduces the underwash effect. For the ECH, similar phenomena were observed.

The use of sandwich structures in helmet liners of the ACH for pressure wave attenuation was studied by Goel [56]. The author proposed to drill channels in the helmet liners, and fill these channels with an incompressible material, either fluid or solid, as shown in Fig. 9. Experimental and computational analyses were carried out on specially prepared samples but not on an actual helmet. Both solid (glass beads, aerogel, or solid foam) and liquid (glycerin, water, or AgileZorb) filler materials were tested. Glycerin was found to have the highest pressure attenuation ability among all filler materials tested. It was revealed that lower-porosity materials (such as glycerin and glass beads) showed lower energy transmission than high-density materials (such as aerogel). The use of glycerin resulted in a $50 \%$ reduction in the peak pressure. However, the use of glycerin led to a considerable increase in the weight of the liners.

\subsection{Damage criteria for brain}

Damage criteria are useful for predicting the probability of TBI under mechanical loading. The currently used injury criterion is the head injury criterion (HIC) adopted by the National Highway Traffic Safety Administration (NHTSA) based on the work of Gadd [47]. The HIC is an empirical criterion mainly used in the automobile industry and is based on the probability of injury due to a global translational head acceleration. While the HIC is useful for predicting injury in automobile accidents, it may not be applicable for predicting blast induced TBI. This is because the HIC is based on global kinematics data to predict injury, whereas the blast-induced TBI is caused by intra cranial mechanical responses. Further, the HIC is based on experimental data, for which only external impact loading is applied. In addition, rotational head accelerations have not been taken into account in developing the HIC. In order to overcome these drawbacks, Newman proposed the Head Impact Power (HIP) criterion [99]. This criterion is based on angular and linear accelerations. However, both these criteria are proposed for impact loading rather than blast loading. The two main known causes of $\mathrm{BTBI}$ are penetration of pressure waves into the skull and rotational acceleration.

In the past decade, many 3-D finite element head models have been used to develop injury criteria for the brain. The Wayne State University (WSU) head model (e.g., [162]), MIT DVBIC head model [104], SIMon head model [138], and University of Louis Pasteur (ULP) head model [157] are some of the popular 3-D head models used in finite element analyses. Recent experimental validation [87] has shown that the SIMon head model gives rather inaccurate results for predicting TBI compared to the ULP model. This has been attributed to the fact that the head model used in the ULP criterion is closer to the real anatomy of a human head than the SIMon model.

Various injury criteria based on stress, strain, strain rate, intracranial pressure gradient, and type of explosives are summarized in Table 6. Except for the criterion reported in Chafi et al. [20], none of the criteria listed in Table 6 have been developed for blast events. All the criteria have been developed for direct impact loading, which is minimal for blast events.

Even though a lot of efforts have been made to understand the mechanisms of TBI, injury thresholds for BTBI remain undetermined. Protective equipment designed using the existing injury criteria may be inadequate. The environment created by a shock wave is quite complex. In addition, pressure waves are initiated inside the intra cranial cavity. The intensity of a blast, nature of explosives used, and standoff distance all affect the brain tissue's response to loading. Superimposing tolerance curves for each kind

Table 6

Various local injury criteria based on pressure gradients, strains, stresses and strain rates.

\begin{tabular}{|c|c|c|c|c|c|}
\hline Criterion & Threshold & Location of injury & Probability (\%) & Application & Reference \\
\hline \multicolumn{6}{|l|}{ Stress } \\
\hline \multirow[t]{4}{*}{ von Mises } & $6-11 \mathrm{kPa}$ & Corpus callosum & 50 & Rat brain/car crash injuries & Shreiber et al. [127] \\
\hline & $8.4 \mathrm{kPa}$ & Corpus callosum & 50 & Footballers (FEM) & Kleiven [77] \\
\hline & $>30 \mathrm{kPa}$ & Brain neurological lesions & 100 & Motorcyclists/footballers & Willinger and Baumgartner \\
\hline & $>16 \mathrm{kPa}$ & Brain neurological lesions & 50 & $\begin{array}{l}\text { Motorcyclists/footballers } \\
\text { (FEM) }\end{array}$ & [157] \\
\hline \multirow[t]{3}{*}{ Shear } & $8-16 \mathrm{kPa}$ & Diffuse axonal injuries & 100 & Sheep brain & Anderson et al. [4] \\
\hline & $11-16.5 \mathrm{kPa}$ & Diffuse axonal Injuries & 100 & Motorcycle Accidents & Claessens et al. [27] \\
\hline & $>10 \mathrm{kPa}$ & Mild TBI & 80 & Footballers (FEM) & Zhang et al. [163] \\
\hline \multicolumn{6}{|l|}{ Strain } \\
\hline$\varepsilon \dot{\varepsilon}$ & $30 / \mathrm{s}$ & Gray matter & 50 & Multiple specimens & Viano and Lovsund [148] \\
\hline$\varepsilon \dot{\varepsilon}$ & $10.1 / \mathrm{s}$ & Gray matter & 50 & Footballers (FEM) & Kleiven [77] \\
\hline \multirow[t]{2}{*}{$\varepsilon, \dot{\varepsilon}$} & $\varepsilon>0.2$ & White matter & 100 & Tissue culture & Morrison et al. [95] \\
\hline & $\dot{\varepsilon}>10 / \mathrm{s}$ & & & & \\
\hline Shear strain & $>0.24$ & Mild TBI & 80 & Footballers (FEM) & Zhang et al. [163] \\
\hline \multirow[t]{2}{*}{ Lagrangian principal strain } & $>0.21$ & Morphological injury & 50 & Guinea pigs & Bain and Meaney [8] \\
\hline & $>0.181$ & $\begin{array}{l}\text { Electrophysiological } \\
\text { impairment }\end{array}$ & & & \\
\hline Cumulative strain & $\geqslant 0.55$ & White matter & 50 & FEM & Takhounts et al. [138] \\
\hline \multicolumn{6}{|l|}{ Intra Cranial Pressure (ICP) } \\
\hline \multirow[t]{4}{*}{ ICP } & $<173 \mathrm{kPa}$ & Concussion & 0 & Animal/human cadavers & Ward et al. [155] \\
\hline & $>235 \mathrm{kPa}$ & & 100 & $(\mathrm{FEM})$ & \\
\hline & $>90 \mathrm{kPa}$ & Injury (coup side) & 50 & Footballers (FEM) & Zhang et al. [163] \\
\hline & $>-76 \mathrm{kPa}$ & Injury (counter coup) & & & \\
\hline \multicolumn{6}{|l|}{ Amount of explosives } \\
\hline \multirow{2}{*}{$\begin{array}{l}0.205 \mathrm{lb} \text { TNT (standoff distance } \\
160 \mathrm{~cm} \text { ) }\end{array}$} & $\mathrm{ICP}>235 \mathrm{kPa}$ & Coup/counter coup side & 100 & FEM & Chafi et al. [20] \\
\hline & $\begin{array}{l}\text { Shear } \\
\text { stress }>16.5 \mathrm{kPa} \\
\text { Principal } \\
\text { strain }>0.22\end{array}$ & Brain stem & & & \\
\hline
\end{tabular}


of head injury and defining the lowest curve as a head injury tolerance criterion might be one way of going forward.

\subsection{Important findings about BTBI}

Some important findings from existing computational and experimental studies about BTBI are summarized below:

1. Storage of in vitro brain tissue creates a pre-conditioning effect. This leads to underestimated results by $30-50 \%$. There is a considerable interspecies variation between the brain tissues [21,107]. Human brain tissue is about 1.3 times stiffer than porcine brain matter, while monkey brain tissue is stiffer than human brain tissue.

2. There are local differences in the brain material properties (heterogeneity). The brain material also shows a non-isotropic behavior $[128,5]$.

3. The skull absorbs very little of the blast pressure wave. Almost all of the incident blast overpressure is transmitted to the intra cranial cavity. In addition, the impedance mismatch among the air, skull material, and cerebrospinal fluid causes considerable pressure amplification across the airskull interface. This pressure amplification continues for hours after the blast.

4. There is no uniform pressure gradient across the cranial cavity after impact. The maximum positive pressure is observed at the point of impact, while the maximum negative pressure is observed opposite to the point of impact. These positive and negative pressure variations cause sudden changes in density, leading to the formation of cavitation bubbles. Collapse of these cavitation bubbles results in brain damages.

5. The blast wind exerts a rotational acceleration on the skull. There is a time-scale lag between the wave impact and rotational head motion. In a rotational head motion, the motion of the brain lags behind the skull because of the difference in inertia. This leads to high shearing stresses on the brainskull connection and in the brain tissue. These injuries are known as diffuse axonal injuries (e.g., [154]).

6. A lateral explosion causes higher pressures and shear stresses in the intra cranial cavity than a frontal explosion.

7. Exposure to a blast acceleration leads to the compression of the thorax and abdomen because of the presence of air-carrying organs. This creates surges in the blood flow, causing an increase in the intra-cranial pressure.

8. The presence of a helmet does not impede stress wave transmission into the intra cranial cavity. The soft tissues of the face are main pathways of wave transmission into the intra cranial cavity. The presence of a face shield can significantly reduce the internal pressure.
9. Optimization of personal protective equipment for mitigation of the effects of a blast impact still needs to be performed.

10. No experimental validation of numerical simulations has been performed. The material models used in the simulations tend to be overly simplified. No material characterization has been performed to evaluate the suitability of these models for predicting actual human brain tissue responses.

11. When a surrogate head model is used in experiments, the relation between the blast response of the surrogate model and the blast response of a human/animal brain tissue is not always clear.

12. The relation between mechanical damage (high stress/ strain) in numerical simulations and functional damage in an actual brain tissue is not very well established. As there is no clearly defined damage criterion for soft tissues, it is difficult to determine what stress/strain magnitude initiates a physical damage.

\section{Constitutive modeling}

As has been mentioned, experiments for studying blast-induced traumatic brain injury are mainly carried out on specially prepared models of human skulls and tissues, mannequins or dolls, and different animals. Numerical simulations are performed on geometrical models of skull and other brain components, with or without a helmet. All these experiments and simulations require constitutive modeling in order to assign appropriate properties to the constructed models to obtain accurate results.

In an experimental study on human brain tissues, Donnelly and Medige [39] investigated shear properties at different strain rates. Brain tissues were obtained from fresh human cadavers. The brain specimens consisted of samples cut from brain cerebrum. The majority of the tests were performed at strain rates of $0,30,60$, and 90/s, with some additional tests performed at 120 and 180/s. Thirty tests were performed at each strain rate, and all the samples were tested up to a shear strain of $100 \%$. The stress-strain curves were fitted with a two-parameter power-law function of the form $\sigma=A \varepsilon^{B}$. A common value of 1.28 was used for the exponent $B$, while the amplitude of $A$ varied with the strain rate. It was found that rate effects were predominant between 0 and 60/s, while no rate effect was observed beyond 60/s. Shafieian et al. [126] performed shear deformation tests on bovine brain tissues at strain rates of $100-750 / \mathrm{s}$. The average shear modulus varied from $11.17 \mathrm{kPa}$ at $100 / \mathrm{s}$ to $22.44 \mathrm{kPa}$ at $750 / \mathrm{s}$. These results validated the hypothesis of Donnelly and Medige [39] that the response of a brain tissue in shear at strain rates higher than 100/s is independent of the strain rate. More discussions on mechanical testing of brain tissues can be found in a comprehensive review paper by Chatelin et al. [21].

Table 7

Properties of some materials used for the US Army Helmets (e.g., [132,66,12,31]).

\begin{tabular}{|c|c|c|c|c|}
\hline Helmet & Material (shell/fabric) & Properties & Shell (matrix) & Fiber (reinforcement) \\
\hline Hadfield & Steel & $\begin{array}{l}\text { Tensile strength (MPa) } \\
\text { Tensile modulus (GPa) } \\
\text { Breaking strain (\%) }\end{array}$ & $\begin{array}{l}250 \\
183 \\
10\end{array}$ & $\begin{array}{l}- \\
- \\
-\end{array}$ \\
\hline PASGT & Thermoset resin/Kevlar ${ }^{\circledR}$ K29 composite & $\begin{array}{l}\text { Tensile strength (MPa) } \\
\text { Tensile modulus (GPa) } \\
\text { Breaking strain (\%) }\end{array}$ & $\begin{array}{l}7386 \\
195 \\
3.8\end{array}$ & $\begin{array}{l}2794 \\
67 \\
3.5\end{array}$ \\
\hline $\mathrm{ACH}$ & Thermoset resin/Kevlar ${ }^{\circledR}$ K129 composite & $\begin{array}{l}\text { Tensile strength (MPa) } \\
\text { Tensile modulus (GPa) } \\
\text { Breaking strain (\%) }\end{array}$ & $\begin{array}{l}7386 \\
195 \\
3.8\end{array}$ & $\begin{array}{l}3429 \\
96 \\
3.3\end{array}$ \\
\hline $\mathrm{ECH}$ & Dyneema ${ }^{\circledR}$ HB80 composite & $\begin{array}{l}\text { Tensile strength (MPa) } \\
\text { Tensile modulus (GPa) } \\
\text { Breaking strain (\%) }\end{array}$ & $\begin{array}{l}\text { Not available } \\
\text { Not available } \\
\text { Not available }\end{array}$ & $\begin{array}{l}2500 \\
120 \\
3.5-3.7\end{array}$ \\
\hline
\end{tabular}


The material properties for the helmet are standard, depending upon the helmet type. The properties of some materials used for helmets are given in Table 7.

Development of material models for biological brain tissues is an area of on-going research (e.g., [71,28]). From the biomechanical perspective, brain is a very complex organ involving many substructures including brain stem, cerebral cortex, and thalamus. Understanding how the loading and kinematic boundary conditions applied to the skull/organ translate into the stress-strain relation of the brain tissue is challenging because of the interplay among a number of factors such as non-linear visco-elasticity, anisotropy, rate dependency, hysteresis behavior in cyclic tension-compression tests, and sensitivity. Many biomechanical, experimental, and numerical studies have been carried out to develop constitutive models for the brain material. The constitutive models developed can be divided into three main categories, as listed below.

\subsection{Linear viscoelastic models}

Linear viscoelastic models (e.g., [54,102]) describe the creep and relaxation responses. Standard viscoelastic models or some variants of them are used to model tissue responses. The number of material constants needed in such a model depends on how many springs and dashpots are used (e.g., [35-38]). However, linear viscoelastic models are suitable only over a small strain regime and are not adequate to describe tissue responses under blast loading.

\subsection{Large strain hyper-elastic models}

The Helmholtz free energy function is ordinarily used to define a hyper-elastic material or Green elastic material. Fung [46] proposed such a function, called a pseudo-strain energy function, to describe a particular aspect of an inelastic material. One approach in hyper-elastic modeling is to use polynomial strain energy functions to describe the material response $[46,147]$. The material parameters used in a polynomial function are numerous and may not have any physical meaning. These models tend to be numerically unstable at high strains [9], violate convexity conditions and do not satisfy the stress-free reference configuration condition. Another approach is to use the invariants of the deformation gradient tensor (e.g., $[69,91,40])$. This approach can be used to describe the anisotropic behavior of soft tissues by decoupling a strain energy density function into contributions from fiber and matrix phases. This is the most often used approach. However, hyper-elastic models represent only elastic or quasi-static deformations. These models alone cannot capture the complexities of the tissue response such as permanent deformations and memory effects. In the decoupled framework, the energy contribution from the matrix depends on the first and second invariants of the CauchyGreen strain tensor, while the fibers are considered as non-linear springs with the energy contribution depending on the fourth invariant of the Cauchy-Green strain tensor. An extensive literature review has shown that almost all current phenomenological models use this approach (e.g., [159,22]). However, a strain energy density function depending only on the fourth invariant is inadequate to describe the brain tissue behavior at medium to high strains, especially for shear loading. This is particularly important for simulating blast injuries, as shearing failures (such as diffuse axonal injuries) are a primary cause of TBI. In addition, the bulk modulus of the brain tissue is considerably higher than the shear modulus $[133,89]$. Therefore, it is necessary that a constitutive model developed to simulate TBI mechanisms accurately characterize the shear as well as the tension/compression behavior of the brain tissue.

\subsection{Large strain hyper-viscoelastic models}

Hyper-viscoelastic constitutive modeling combines the methodologies of linear viscoelasticity and hyper-elasticity.

The Mooney-Rivlin hyper-elastic model and the Neo-Hookean material model are the most commonly used constitutive equations to represent quasi-static responses of brain tissues. For example, Mendis [90] used hyper-viscoelastic modeling to characterize large deformations of brain tissues. The quasi-static deformation (hyper-elastic part) was represented by an incompressible two parameter Mooney-Rivlin model. The material parameters for the viscoelastic model were determined by fitting with experimental data from rate-dependent compression tests. Wang and Wineman [152] constructed a continuum mechanics model for the probe test of Fallenstein and Hulce [44] by treating the brain tissue as a homogenous, isotropic, linear, viscoelastic material. They assumed that the skull is entirely filled by the brain and the skull is rigid with zero deformation. Also, the shear effects at the brain-skull interface are ignored in their model. A numerical method was implemented to solve for the shear stress relaxation functions in terms of measured displacements and forces by the probe.

Darvish and Crandall [33] proposed a third-order non-linear Green-Rivlin viscoelastic model and compared it with a third-order quasi-linear viscoelastic model. For both the models, the elastic response was represented by a second-order Rivlin strain energy density function. They also tested bovine brain tissues in simple shear using forced vibrations from 0.5 to $200 \mathrm{~Hz}$ up to a Lagrangian shear strain of $20 \%$. The third-order non-linear properties were characterized by applying simple, double, and triple harmonic inputs. The fully non-linear Green-Rivlin model also contains intermodular distortions: frequency combinations of the fundamental frequencies and their integer harmonics. This study was continued by Takhounts et al. [139], where bovine and human brain tissues were compared. A linear viscoelastic shear strain limit of $17.5 \%$ was established for the brain tissues. The quasi-linear viscoelastic model was found to be suitable up to a strain value of $50 \%$, while the Green-Rivlin non-linear model was seen to work for any shear strain range.

Hyper-viscoelastic models also use a decoupled representation of the Helmholtz free energy function. One way is to decompose the total deformation gradient tensor into an elastic part and a viscoelastic part. El Sayed et al. [43] and Prevost et al. [111] developed two non-linear models based on this decomposition technique. El Sayed et al. [43] proposed a generalized framework where a number of Maxwell-type relaxation viscoelastic networks were considered in parallel with viscoplastic networks. The number of material constants adopted varied with the number of networks used. By utilizing this model, they were able to capture the hysteretic and dissipative characteristics of soft tissues in tension up to a strain of 50\%. Prevost et al. [111] used an elastic network to represent instantaneous deformations and a viscoelastic network for dissipative responses. Hrapko et al. [70] used a Mooney-Rivlin viscoelastic network along with a non-linear hyper-elastic spring to model shear and compressive responses up to a strain rate of $1 / \mathrm{s}$. This methodology of decomposing the deformation gradient tensor into an elastic part and a viscoelastic part is based on the theory developed by Lee [82]. However, this decomposition is built upon the assumptions that the body is isotropic in the reference configuration and the origin in the stress space always lies inside the body [60]. Therefore, this method cannot be extended to model the anisotropic response of a soft tissue. Another way of implementing hyper-viscoelastic models is to decompose the deformation gradient tensor into a dilatational part and a volume-preserving part. This method, unlike the one by Lee [82], is not restricted to isotropy. This volume preserving and volume changing decomposition technique has been used to develop constitutive models for knee 
ligaments and tendons [108], musculoaponeurotic system and facial skin tissue [122], bovine liver tissue [119], porcine brain tissue [70], arteries [69], and caterpillar muscle [40]. All these models have been developed to capture tissue responses in a uniaxial tension and have been validated for a limited range of loading regimes and low strain rates. Several studies have been conducted to determine the range of strains and strain rates associated with TBI. Strains greater than $10 \%$ and strain rates greater than $10 /$ s have been observed to cause severe damage to brain tissues [116]. Therefore, any material model developed to capture brain tissue responses in blast events should be able to represent different mechanical behaviors (and loading regimes) in one general framework and should be validated for large strains and high strain rates.

\section{Concluding remarks}

The design, materials, performance measures, and energy absorption mechanisms of various US Army combat helmets are discussed in this review article. It has been found that curvature has a significant effect on the ballistic limit of a helmet (as a laminated composite shell). Development of 3-D scanning techniques has opened up new avenues for head and helmet sizing. Computer aided design along with 3-D laser scanning can be used to obtain accurate information about head size variations and generate appropriate helmet sizes. Ballistic performance measures of conventional helmet materials (such as Kevlar ${ }^{\circledR}$ K29, K129 fibers and thermoset polymers) and new materials (like UHMWPE, thermoplastic polymers, nano-composites, and CNTs) are elaborated in view of weight, tensile properties, energy absorption capabilities, manufacturing ease, cost effectiveness, and environmental concerns. It has become known that UHMWPE/carbon fiber composites can provide higher ballistic protection at a reduced weight than the composites used in the current helmets. Polymer matrix nano-composites, especially those reinforced by carbon nanotubes, can potentially offer the highest ballistic protection. However, their viability in terms of manufacturing feasibility and cost effectiveness needs to be further explored.

Blast induced traumatic brain injury has been a signature injury of Iraq and Afghanistan conflicts. Numerous experimental and computational studies have been conducted to determine brain responses to blast waves and helmet effectiveness against blast events. Passage of blast waves through skull and thoracic mechanisms have been identified as possible causes of TBI. Regarding the effectiveness of the current helmets against blast waves, the limited studies available in the literature present contradictory results. There has been no consensus about whether the current helmet designs are effective for preventing blast induced traumatic brain injury (BTBI). Helmets with face shields have been suggested as a possible modification to the current helmet designs to prevent BTBI. The material models used in published BTBI simulations tend to be overly simplified and remain to be experimentally validated. It is necessary to verify the suitability of these models for representing brain tissue behaviors in different loading regimes. While the mechanisms behind BTBI have been getting better understood, there is an urgent need for identifying TBI injury criteria, developing experimental models for validating computational simulations, and optimizing the current head protection equipment to mitigate occurrence of blast induced traumatic brain injuries.

\section{Acknowledgements}

The work reported here is partially funded by the US Army. This support is gratefully acknowledged. The authors also thank Prof. Antonio Ferreira and two anonymous reviewers for their encouragement and helpful comments on an earlier version of the paper.
The views and conclusions contained herein are those of the authors and should not be interpreted as necessarily representing the official policies or endorsements, either expressed or implied, of the US Army.

\section{References}

[1] Aare M, Kleiven S. Evaluation of head response to ballistic helmet impacts using the finite element method. Int J Impact Eng 2005; 34(3):596-608

[2] Alley MD, Schimizze BR, Son SF. Experimental modeling of explosive blast related traumatic brain injuries. Neurolmage 2010;54(Suppl. 1):45-54.

[3] Alves ALdS, Nascimento LFC, Suarez JCM. Influence of weathering and gamma irradiation on the mechanical and ballistic behavior of UHMWPE composite armor. Polym Testing 2005;24(1):104-13.

[4] Anderson RWG, Brown CJ, Blumbergs PC, Scott G, Finney JW, Jones NR, et al Mechanisms of axonal injury: an experimental and numerical study of a sheep model of head impact. In: Proceedings of the 1999 international conference on the biomechanics of impact. International research council on the biokinetics of impact (IRCOBI), Sitges, Spain, September 23-24, 1999.

[5] Arbogast KB, Margulies SS. Material characterization of the brainstem from oscillatory shear tests. J Biomech 1998;31:801-7.

[6] Arinstein A, Burman M, Gendelman O, Zussman E. Effect of supramolecular structure on polymer nanofibre elasticity. Nat Nanotechnol 2007;2:59-62.

[7] Barber AH, Cohen SR, Kenig S, Wagner HD. Measurement of carbon nanotubepolymer interfacial strength. Appl Phys Lett 2003;82(23):4140-2.

[8] Bain AC, Meaney DF. Tissue level thresholds for axonal damage in an experimental model of central nervous systems white matter injury. J Biomech Eng 1998;122(6):615-22.

[9] Balzani D, Neff P, Schroder J, Holzapfel GA. A polyconvex framework for soft biological tissues. Adjustment to experimental data. Int J Solids Struct 2006;43:6052-70.

[10] Bauman RA, Ling G, Tong L, Januszkiewicz A, Agoston D, Delanerolle N, et al. An introductory characterization of a combat casualty care relevant swine model of closed head injury resulting from exposure to explosive blast. J Neurotrauma 2009;26(6):841-60.

[11] Bazhenov S. Dissipation of energy by bulletproof aramid fabric. J Mater Sci 1997;32(15):4167-73.

[12] Bilisik AK, Turhan Y. Multidirectional stitched layered aramid woven fabric structures and their experimental characterization of ballistic performance. Text Res J 2009;79(14):1331-43.

[13] Bouamoul A, Williams K, Levesque H. Experimental and numerical modelling of a mannequin for the assessment of blast incapacitation and lethality under blast loading. In: Proceedings of the 23rd international symposium on ballistics, Tarragona, Spain, April 16-20, 2007. p. 1189-96.

[14] Bowen IG, Fletcher ER, Richmond DR. Estimate of man's tolerance to the direct effects of air blast. Technical report DASA 2113. Washington, DC: Defense Atomic Support Agency; 1968.

[15] Budiansky B. On the elastic moduli of some heterogeneous materials. J Mech Phys Solids 1965;13(1965):223-7.

[16] Carey ME, Herz M, Corner B, McEntire J, Malabarba D, Paquette S, et al. Ballistic helmets and aspects of their design. Neurosurgery 2000;47(3):678-89.

[17] Cannon L. Behind armour blunt trauma - an emerging problem. J R Army Med Corps 2001;147:87-96.

[18] Carroll AW, Soderstrom CA. A new nonpenetrating ballistic injury. Ann Surg 1978;188:753-7.

[19] Cernak I, Haeusslein LJN. Traumatic brain injury: an overview of pathobiology with emphasis on military populations. J Cereb Blood Flow Metab 2010;30(2):255-66.

[20] Chafi MS, Karami G, Ziejewski M. Biomechanical assessment of brain dynamic responses due to blast pressure waves. Ann Biomed Eng 2009;38(2):490-504

[21] Chatelin S, Constantinesco A, Willinger R. Fifty years of brain tissue mechanical testing: from in vitro to in vivo investigations. Biorheology 2010;47:255-76.

[22] Chatelin S, Deck C, Willinger R. An anisotropic viscous hyperelastic constitutive law for brain material finite-element modeling. J Biorheol 2012. http://dx.doi.org/10.1007/s12573-012-0055-6.

[23] Chavko M, Koller WA, Prusaczyk WK, McCarron RM. Measurement of blast wave by a miniature fiber optic pressure transducer in the rat brain. Neurosci Methods 2007;159(2):277-81.

[24] Chen B. Polymer-clay nanocomposites: an overview with emphasis on interaction mechanisms. Br Ceram Trans 2004;103(6):241-9.

[25] Chen Y, Ostoja-Starzewski M. MRI-based finite element modeling of head trauma: spherically focusing shear waves. Acta Mech 2010;213(1-2):155-67.

[26] Cheng KC, Chen YL. Ballistic-proof effects of various woven constructions Fibers Text Eastern Europe 2010;18(6):63-7.

[27] Claessens M, Sauren F, Wismans J. Modeling of human head under impact conditions. In: Proceedings of the 41st STAPP Car Crash conference, Lake Buena Vista, Florida, November 13-14, 1997. SAE paper no. 973338.

[28] Clayton EH, Genin GM, Bayly PV. Transmission, attenuation and reflection of shear waves in the human brain. J R Soc Interface 2012;9:2899-910.

[29] Courtney A, Courtney M. A thoracic mechanism of mild traumatic brain injury due to blast pressure waves. Med Hypotheses 2009;72(1):76-83. 
[30] Cullis IG. Blast waves and how they interact with structures. J R Army Med Corps 2001;147(1):16-26.

[31] Czechowski L, Jankowski J, Kubiak T. Experimental tests of a property of composite material assigned for ballistic products. Fibers Text Eastern Europe 2012;20(3):61-6.

[32] Dalton AB, Collins S, Razal J, Munoz E, Ebron VH, Kim BG, et al. Continuous carbon nanotube composite fibers: properties, potential applications, and problems. J Mater Chem 2003;14(1-3):1-3.

[33] Darvish KK, Crandall JF. Nonlinear viscoelastic effects in oscillatory shear deformation of brain tissue. Med Eng Phys 2001;23:633-45.

[34] David NV, Gao X-L, Zheng JQ. Ballistic resistant body armor: contemporary and prospective materials and related protection mechanisms. Appl Mech Rev 2009;62(5). 050802-1 20.

[35] David NV, Gao X-L, Zheng JQ. Modeling of viscoelastic behavior of ballistic fabrics at low and high strain rates. Int J Multiscale Comput Eng 2009;7(4):295-308.

[36] David NV, Gao X-L, Zheng JQ. Constitutive behavior of a Twaron ${ }^{\circledR} /$ natural rubber composite. Mech Adv Mater Struct 2010;17(4):246-59.

[37] David NV, Gao X-L, Zheng JQ. Stress relaxation of a Twaron ${ }^{\circledR} /$ natural rubber composite. ASME J Eng Mater Technol 2011;134(3). 011001-1 9.

[38] David NV, Gao X-L, Zheng JQ. Creep of a Twaron ${ }^{\circledR} /$ natural rubber composite. Mech Adv Mater Struct, in press. http://dx.doi.org/10.1080 15376494.2012.676719.

[39] Donnelly BR, Medige J. Shear properties of human brain tissue. J Biomech Eng 1997;119(4):423-32.

[40] Dorfmann AL, Woods WAJ, Trimmer BA. Muscle performance in a soft-bodied terrestrial crawler: constitutive modelling of strain-rate dependency. J R Soc Interface 2007;5(20):349-62.

[41] Dubnikova IL, Berezina SM, Antonov AV. Effect of rigid particle size on the toughness of filled polypropylene. J Appl Polym Sci 2004;94(5):1917-26.

[42] Eitan A, Fisher FT, Andrews R, Brinson LC, Schadler LS. Reinforcement mechanisms in MWCNT-filled polycarbonate. Compos Sci Technol 2006;66(9):1162-73.

[43] El Sayed T, Mota A, Fraternali F, Ortiz M. Biomechanics of traumatic brain injury. Comput Methods Appl Mech Eng 2008;197(51-52):4692-701.

[44] Fallenstein GT, Hulce VD. Dynamic mechanical properties of human brain tissue. J Biomech 1969;2:217-26.

[45] Faur-Csukat G. A study on the ballistic performance of composites. Adv Polym Compos Technol 2006;239(1):217-26.

[46] Fung YC. Elasticity of soft tissues in simple elongation. Am J Physiol 1967;213(6):1532-44

[47] Gadd CW. Use of weighted-impulse criterion for estimating injury hazard. In: Proceedings of the 10th STAPP Car Crash conference, Alamogordo, New Mexico, November 8-9, 1966. SAE paper no. 660793.

[48] Gama BA, Bogetti TA, Fink BK, Yu C-J, Claar TD, Eifert HH, et al. Aluminum foam integral armor: a new dimension in armor design. Compos Struct 2001;52(3-4):381-95

[49] Ganpule S, Gu L, Chandra N. MRI-based three dimensional modeling of blast traumatic brain injury (bTBI). In: Proceedings of the ASME 2010 international mechanical engineering congress and exposition, Vancouver, Canada, November 12-18, 2010. Paper \# IMECE2010-39428.

[50] Ganpule S, Gu L, Alai A, Chandra N. Role of helmet in the mechanics of shock wave propogation under blast loading conditions. Comput Methods Biomech Biomed Eng 2011;10:1-12.

[51] Gao X-L, Li K. Finite deformation continuum model for single-walled carbon nanotubes. Int J Solids Struct 2003;40:7329-37.

[52] Gao X-L, Li K. A shear-lag model for carbon nanotube-reinforced polymer composites. Int J Solids Struct 2005;42:1649-67.

[53] Gao X-L, Mall S. A two-dimensional rule-of-mixtures micromechanics model for woven fabric composites. ASTM J Compos Technol Res 2000;22:60-70.

[54] Gefen A, Gefen N, Zhu QL, Raghupati R, Margulies SS. Age-dependent changes in material properties of the brain and brain case of the rat. J Neurotrauma 2003;20:1163-77.

[55] Gibson RF. A review of recent research on the mechanics of multifunctional composite materials and structures. Compos Struct 2010:92(12):2793-810.

[56] Goel R. Study of an advanced helmet liner concept to reduce TBI: experiments and simulation using sandwich structures. Master's thesis. Massachusetts Institute of Technology, Cambridge; 2011. 104 p.

[57] Goggio AF. The mechanism of contre-coup injury. J Neurol Psychiatry $1941 ; 1: 11-22$

[58] Gogineni S, Gao X-L, David NV, Zheng JQ. Ballistic impact of Twaron CT709 ${ }^{\circledR}$ plain weave fabrics. Mech Adv Mater Struct 2012;19(6):441-52.

[59] Gojny FH, Wichmann MHG, Fiedler B, Schulte K. Influence of different carbon nanotubes on the mechanical properties of epoxy matrix composites - a comparative study. Compos Sci Technol 2005;65(15-16):2300-13.

[60] Green AE, Naghdi PM. Some remarks on elastic-plastic deformation at finite strain. Int J Eng Sci 1971;9:1219-29.

[61] Grujicic M, Arakere G, He T. Material-modeling and structural mechanics aspects of the traumatic brain injury problem. Multidiscipl Model Mate Struct 2009;6(3):335-63.

[62] Grujicic M, Bell WC, Pandurangan B, Glomski PS. Fluid/structure interaction computational investigation of blast-wave mitigation efficacy of the advanced combat helmet. J Mater Eng Perform 2010;20(6):877-93.

[63] Grujicic M, Bell WC, Pandurangan B, He T. Blast-wave impact-mitigation capability of polyurea when used as helmet suspension-pad material. Mater Des 2010;31(9):4050-65.
[64] Guo F, Wang L, Dong D. Human head 3D dimensions measurement for the design of helmets. Lect Notes Comput Sci 2009;5620:624-31.

[65] Hisley DM, Gurganus JC, Drysdale AW. Experimental methodology using digital image correlation to assess ballistic helmet blunt trauma. ASME J Appl Mech 2011:78. 051022-1 7.

[66] Hearle JWS. High performance fibers. Cambridge, England: Woodhead Publishing; 2001.

[67] Herold D, Griffiths L, Fung TY. Lightweight, high bandwidth conformal antenna system for ballistic helmets. In: Military communications conference (MILCOM), IEEE, Orlando, Florida, October 29-31, 2007. 6 p.

[68] Holbourn AHS. The mechanics of brain injuries. $\mathrm{Br}$ Med Bull 1945;3(6):147-9.

[69] Holzapfel GA, Gasser TC. A new constitutive framework for arterial wall mechanics and a comparative study of material models. J Elast 2000;61(13):1-48.

[70] Hrapko M, van Dommelen JAW, Peters GWM, Wismans JSHM. Characterisation of the mechanical behaviour of brain tissue in compression and shear. Biorheology 2008;45(6):663-76.

[71] Hrapko M, van Dommelen JAW, Peters GWM, Wismans JSHM. On the consequences of non linear constitutive modelling of brain tissue for injury prediction with numerical head models. Int J Crashworthiness 2009; 14(3):245-57.

[72] Ivins BJ, Schwab KA, Crowley JS, McEntire J, Trumble CC, Brown FH, et al. How satisfied are soldiers with their ballistic helmets? A comparison of soldiers' opinions about the advanced combat helmet and the personal armor system for ground troops helmet. Mil Med 2007;172(6):586-91.

[73] Jason AM. Facial protective devices for blast-induced traumatic brain injury mitigation. Master's thesis. Massachusetts Institute of Technology, Cambridge; 2010. 77 p.

[74] Kalgaonkar RA, Jog JP. Effects of modifier concentration on structure and viscoelastic properties of copolyester/clay nanocomposites. J Macromol Sci Part B - Phys 2004;43(2):421-36.

[75] Keyak JH, Meagher JM, Skinner HB, Mote CD. Automated three-dimensional finite element modelling of bone: a new method. J Biomed Eng 1990;12(5):389-97.

[76] Kirkman E, Watts S. Characterization of the response to primary blast injury. Philos Trans R Soc Lond B Biol Sci 2011;366:286-90.

[77] Kleiven S. Biomechanics and thresholds for MTBI in humans. In: Proceedings of the international brain injury association's seventh world congress, Lisbon, Portugal, April 9-12, 2008.

[78] Koziol K, Vilatela J, Moisala A, Motta M, Cunniff P, Sennett M, et al. High performance carbon nanotube fiber. Science 2007;318(5858):1892-5.

[79] Laible RC. Ballistic materials and penetration mechanics. Amsterdam: Elsevier; 1980

[80] Lau KT, Gu C, Hui D. A critical review on nanotube and nanotube/nanoclay related polymer composite materials. Compos Part B: Eng 2006;37:425-36.

[81] Laurenzi S, Pastore R, Giannini G, Marchetti M. Experimental study of impact resistance in multi-walled carbon nanotube reinforced epoxy. Compos Struct 2013;99:62-8

[82] Lee EH. Elastic-plastic deformation at finite strains. ASME J Appl Mech 1969;38:1-6.

[83] Lee KY, Nyein KM, Moore DF, Joannopoulus JD, Socrate S, Imholt T, et al. Blastinduced electromagnetic fields in the brain from bone piezoelectricity. Neuroimage 2010;54(Suppl. 1):30-6.

[84] Li C, Chou TW. A structural mechanics approach for the analysis of carbon nanotubes. Int J Solids Struct 2003;40(2003):2487-99.

[85] Lopatnikov SL, Gama BA, Haque MJ, Krauthauser C, Gillespie JW, Guden M et al. Dynamics of metal foam deformation during Taylor cylinder-Hopkinson bar impact experiment. Compos Struct 2003;61:61-71.

[86] Ma Z, Sun C, Cui Y, Liu Y, Hulbert GM, Raju B, et al. Simulation and test of nanocomposites for application in the army. In: The 27th army science conference, Orlando, FL, November 29-December 2, 2010. 8 p.

[87] Marjoux D, Baumgartner D, Deck C, Willinger R. Head injury prediction capability of the HIC, HIP, SIMon, and ULP criteria. Accident Anal Prevent 2006;40:1135-48

[88] Mayorga MA. The pathology of primary blast overpressure injury. Toxicology 1997;121(1):17-28.

[89] McElhaney JH, Roberts VL, Hilyard JF. Handbook of human tolerance. Japan Automobile Research Institute; 1976. 143 p.

[90] Mendis K. Finite element modeling of the brain to establish diffuse axonal injury criteria. Ph.D. dissertation. The Ohio State University, Columbus, $\mathrm{OH}$; 1992.

[91] Merodio J, Ogden RW. Instabilities and loss of ellipticity in fiber-reinforced compressible non-linearly elastic solids under plane deformation. Int J Solids Struct 2003:40:4707-27.

[92] Micheli D, Gardoni G, Pastore R, Apollo C, Marchetti M. Ballistic characterization of nanocomposite materials by means of "Coil Gun" electromagnetic accelerator. In: Proceedings of the XIX international conference on electrical machines, IEEE, Rome, Italy, September 6-8, 2010. $6 \mathrm{p}$.

[93] Moore DF, Jerusalem A, Nyein M, Noels L, Jaffee MS, Radovitzky RA. Computational biology - modeling primary blast effects on the central nervous system. NeuroImage 2009;47(Suppl. 2):T10-20.

[94] Morka A, Jackowska B. Ballistic resistance of the carbon nanotube fibres reinforced composites - numerical study. Comput Mater Sci 2011; 50(4):1244-9. 
[95] Morrison B, Cater HL, Wang CB, Thomas FC, Hung CT, Ateshian GA, et al. A tissue level tolerance criterion for living brain developed with an In-Vitro model of TRaumatic Mechanical Loading. Stapp Car Crash J 2003;47:93-105.

[96] Moss WC, King MJ, Blackman EG. Skull flexure from blast waves: a mechanism for brain injury with implications for helmet design. Phys Rev Lett 2009:103. 108702-1 4

[97] Mylvaganam K, Zhang LC. Ballistic resistance capacity of carbon nanotubes. Nanotechnology 2007;18(47):5701-4.

[98] Naik NK, Shrirao P. Composite structures under ballistic impact. Compos Struct 2004;66(1-4):579-90.

[99] Newman JA, Shewchenko N, Welbourne E. A new biomechanical head injury assessment function: the maximum power index. In: Proceedings of the 44th STAPP Car Crash conference, Atlanta, Georgia, November 6-8, 2000. SAE paper no. 2000-01-SC16.

[100] Nguyen, T. Effects of curvature on the stress of a curved laminated beam subjected to bending. Master's thesis, University of Texas at Arlington; 2010. $90 \mathrm{p}$.

[101] Ni B, Sinnott SB. Tribological properties of carbon nanotube bundles predicted from atomistic simulations. Surf Sci 2001:487(1-3):87-96

[102] Nicolle S, Lounis M, Willinger R. Shear properties of brain tissue over a frequency range relevant for automotive impact situations: new experimental results. Stapp Car Crash J 2004;48:239-58.

[103] Nilakantan G, Keefe M, Wetzel ED, Bogetti TA, Gillespie JW. Computational modeling of the probabilistic impact response of flexible fabrics. Compos Struct 2011;93:3163-74.

[104] Nyein MK, Jason AM, Yu L, Pita CM, Joannopoulos JD, Moore DF, et al. In silico investigation of intracranial blast mitigation with relevance to military traumatic brain injury. Proc Natl Acad Sci 2010;109(23):20703-8.

[105] Obreja C. The stereotactical phenomena in traumatic brain injury biomechanics-diffuse axonal injury and brain concussion. Restorative Neurol Neurosci 1999;16(3-4):310-1.

[106] Panel on Human Factors in the Design of Tactical Display Systems for the Individual Soldier. Physical ergonomics of infantry helmet. In: Tactical display for soldiers: human factors consideration. Washington, DC: National Academy Press; 1997. p. 205-16

[107] Pervin F, Chen W. Effect of inter-species, gender, and breeding on the mechanical behavior of brain tissue. NeuroImage 2011;54(S1): S98-S102.

[108] Pioletti DP. Viscoelastic properties of soft tissues: application to knee ligaments and tendons. J Biomech 1997:31(8):753-7.

[109] Popov VN. Carbon nanotubes: properties and applications. Mater Sci Eng 2004;43:61-102.

[110] Prat N, Rongieras F, Sarron J-C, Miras A, Voiglio E. Contemporary body armor: technical data, injuries, and limits. Eur J Trauma Emerg Surg 2012;38:95-105.

[111] Prevost TP, Balakrishnan A, Suresh S, Socrate S. Biomechanics of brain tissue. Acta Biomater 2011;7(1):83-95.

[112] Qi B, Zhang QX, Bannister M, Mai YW. Investigation of the mechanical properties of DGEBA-based epoxy resin with nanoclay additives. Compos Struct 2006;75(1-4):514-9

[113] Rafiee R, Moghadam RM. Simulation of impact and post-impact behavior of carbon nanotube reinforced polymer using multi-scale finite element modeling. Comput Mater Sci 2012;63:261-8.

[114] Raju B, Jiang D, Cui Y, Liu Y. Simulation and design of nanocomposite for application in ballistic protection. In: Proceeding of the 26th army science conference, Orlando, Florida, December 1-4, 2008. 8 p.

[115] Rash CE, Verona RW, Crowley JS. Human factors and safety considerations of night vision systems flight using thermal imaging systems. Fort Rucker Alabama: U.S. Army Aeromedical Research Laboratory. USAARL report no. 90-10; 1990. 20 p.

[116] Rashid B, Destrade M, Gilchrist M. Mechanical characterization of brain tissue in compression at dynamic strain rates. J Mech Behav Biomed Mater 2012;10:23-38.

[117] Reneker DH, Chun I. Nanometre diameter fibers of polymer produced by electrospinning. Nanotechnology 1996;7(3):216-23.

[118] Risdall JE, Menon DK. Traumatic brain injury. Philos Trans R Soc Lond B Biol Sci 2011;366(1562):241-50.

[119] Roan E, Vemaganti K. Strain rate dependent viscohyperelastic constitutive modeling of bovine liver tissue. Med Biol Eng Comput 2010;49(4): 497-506.

[120] Robinnette KM, Vannier MW, Rioux M, Jones PRM. 3-D surface anthropometry: a review of technologies. France: North Atlantic Treaty Organization, Neuilly-Sur-Seine. Advisory group for aerospace research and development report \# 329; 1997. 50 p.

[121] Roland CM, Fragiadakis D, Gamache RM. Elastomer-steel laminate armor. Compos Struct 2010;92:1059-64

[122] Rubin MB, Bodner SR. A three-dimensional nonlinear model for dissipative response of soft tissue. Int J Solids Struct 2001;39(19):5081-99.

[123] Rustemeyer J, Kranz V, Bremerich A. Injuries in combat from 1982-2005 with particular reference to those to the head and neck: a review. Br J Oral Maxillofac Surg 2007;45(7):556-60.

[124] Sarron J-C, Caillou J-P, Da Cunha J, Allain J-C, Tramecon A. Consequences of nonpenetrating projectile impact on a protected head: study of rear effects of protections. J Trauma 2000;49:923-9.

[125] Savage SJ, Gedde UW. Polymer-based nanocomposites for defence applications - a brief overview. Chem Mater 2005;12(3):608-22.
[126] Shafieian M, Bao K, Darvish K. Mechanical properties of brain tissue in strain rates of blast injury. In: 37th Annual northeast bioengineering conference, Troy, NY, April 1-3, 2011. http://dx.doi.org/10.1109/NEBC.2011.5778711.

[127] Shreiber D, Bain A, Meaney D. In vivo thresholds for mechanical injury to the blood-brain barrier. In: Proceedings of the 41st Stapp Car Crash Conference. Lake Buena Vista, Florida, November 13-14, 1997. SAE paper no. 973335.

[128] Shuck LZ, Advani SH. Rheological response of human brain tissue in shear. ASME J Basic Eng 1972;94:905-11.

[129] Simonds J. Non-lethal weapons human effects. Brooks City-Base, TX: Air Force Research Laboratory; 2008. 19 p (PPT file).

[130] Smith O. Explosive blast injury. J R Army Med Corps 1981;125:4-16.

[131] Sogbesan EA. Design and analysis of blast induced traumatic brain injury mechanism using a surrogate headform: instrumentation and outcomes. Master's thesis. University of Nebraska-Lincoln; 2011. 104 p.

[132] Song, JW. Thermoplastic composite for ballistic application. Ph.D. dissertation. University of Massachusetts at Lowell; $1986.118 \mathrm{p}$.

[133] Stalnaker RL. Mechanical properties of the head. Ph.D. dissertation. West Virginia University, Morgantown; 1969.

[134] Stoyanovski M. Grozeva M. Current concepts on the morphogenesis of craniocerebral injuries. Trakia J Sci 2005;3(4):1-5.

[135] Stuhmiller JH. Blast injury-translating research into operational medicine. Washington, DC: Borden Institute; 2008

[136] Stuhmiller JH, Stuhmiller LM. A mathematical model of ventilation response to inhaled carbon monoxide. J Appl Physiol 2005;98(6):2033-44.

[137] Sun L, Gibson RF, Gordaninejad F, Suhr J. Energy absorption capability of nanocomposites: a review. Compos Sci Technol 2009;69:2392-409.

[138] Takhounts EG, Eppinger RH, Campbell JQ, Tannous RE, Power ED, Shook LS On the development of the SIMon finite element model. Stapp Car Crash J 2003;47:107-33.

[139] Takhounts EG, Crandall JF, Darvish K. On the importance of nonlinearity of brain tissue under large deformations. Stapp Car Crash J 2003;47:79-92.

[140] Taylor GI. The formation of a blast wave by a very intense explosion I. Theoretical discussion. Proc R Soc Lond 1950;201(1065):159-74.

[141] Taylor GI. The formation of a blast wave by a very intense explosion. II. The atomic explosion of 1945. Proc R Soc Lond. Ser A, Math Phys Sc 1950;201(1065):175-86.

[142] Taylor PA, Ford CC. Simulation of blast-induced early-time intracranial wave physics leading to traumatic brain injury. J Biomech Eng 2009;131(6). 061007-1 11.

[143] Teland JA. Numerical simulation of blast-induced mild traumatic brain injury. IFMBE Proc 2010;31(Part 2):350-3.

[144] Tham CY, Tan VBC, Lee HP. Ballistic impact of a KEVLAR helmet: experiment and simulations. Int J Impact Eng 2007;35:304-18.

[145] Thompson RF. The brain: an introduction to neuroscience. Cambridge, England: Worth Publishers; 2000.

[146] van Hoof J, Cronin DS, Worswick MJ, Williams KV, Nandlall D. Numerical head and composite helmet models to predict blunt trauma. In: Proceedings the 19th international symposium of ballistics, Interlaken, Switzerland, May 711, 2001. Paper \# VM 06. 8 p.

[147] Velardi F, Fraternali F, Angelillo M. Anisotropic constitutive equations and experimental tensile behavior of brain tissue. Biomech Model Mechanobiol 2006;5(1):53-61.

[148] Viano DC, Lovsund P. Biomechanics of brain and spinal-cord injury: analysis of neuropathologic and neurophysiologic experiments. J Crash Prev Inj Control 1999;1:35-43.

[149] Volkova EI, Jones IA, Brooks R, Zhu Y, Bichoutskaia E. Meso-scale modelling of shock wave propagation in a $\mathrm{SiC} / \mathrm{Al}$ nanocomposite reinforced with $\mathrm{WS}_{2}$ inorganic fullerene nanoparticles. Compos Struct 2013;96:601-5.

[150] Walsh SM, Scott BR, Spagnuolo DM. The development of a hybrid thermoplastic ballistic material with applications to helmets. U.S. Army Research Laboratory, Aberdeen Proving Ground, MD. ARL-TR-3700; 2005. 19 p.

[151] Walsh SM, Scott BR, Spagnuolo DM, Wolbert JP. Hybridized thermoplastic aramids: enabling material technology for future force headgear. Aberdeen Proving Ground, MD: U.S. Army Research Laboratory; 2006. 8 p.

[152] Wang HC, Wineman AS. A mathematical model for the determination of viscoelastic behavior of brain in vivo - II relaxation response. J Biomech 1972;5:571-80.

[153] Wang K, Chen I, Wu JS, Toh ML, He CB, Yee AF. Epoxy nanocomposites with highly exfoliated clay: mechanical properties and fracture mechanisms. Macromolecules 2005;38(3):788-800.

[154] Wang H-C, Ma Y-B. Experimental models of traumatic axonal injury. J Clin Neurosci 2010;17:157-62.

[155] Ward CC, Chan M, Nahum AM. Intracranial pressure - a brain injury criterion. In: Proceedings of the 24th Stapp Car Crash Conference, Troy, Michigan, October 15-17, 1980. SAE Paper No. 801304.

[156] Wichmann MHG, Schulte K, Wagner HD. On nanocomposite toughness Compos Sci Technol 2008;68(1):329-31.

[157] Willinger R, Baumgartner D. Numerical and physical modelling of the human head under impact-toward new injury criterion. Int J Veh Des 2001;32(12):94-115.

[158] Wilson C. Improvised explosive devices (IEDs) in Iraq and Afghanistan: effects and countermeasures. Washington, DC: Congressional Research Service. Order Code RS22330; 2007. 6 p.

[159] Wright RM, Ramesh KT. An axonal strain injury criterion for traumatic brain injury. Biomech Model Mechanobiol 2012;11(1-2):245-60. 
[160] Xiong D. Friction and wear properties of UHMWPE composites reinforced with carbon fibers. Mater Lett 2004;59(2-3):175-9.

[161] Yan L, Ball R, Justice L. The 3D Chinese head and face modeling. Comput Aided Des 2011;44(1):40-7.

[162] Zhang J, Pintar F, Yoganandan N, Gennarelli T, Son S. Experimental study of blast induced traumatic brain injury using a physical head model. Stapp Car Crash J 2009;53:215-27.
[163] Zhang L, Yang KH, King AI. A proposed injury threshold for mild traumatic brain injury. ASME J Biomech Eng 2004;126(2):226-36.

[164] Zhou SJ, Beazley DM, Lomdahl PS, Holian BL. Large-scale molecular dynamics simulations of three-dimensional ductile failure. Phys Rev Lett 1997:78(3):479-82.

[165] Zuiderduin WCJ, Westzaan C, Huetink J, Gaymans RJ. Toughening of polypropylene with calcium carbonate particles. Polymer 2003;44(1):261-75. 